\title{
A THEORETICAL AND EMPIRICAL STUDY OF THE RESPONSE OF THE HIGH LATITUDE THERMOSPHERE TO THE SENSE OF THE " $Y$ " COMPONENT OF THE INTERPLANETARY MAGNETIC FIELD
}

\author{
D. REES, T. J. FULLER-ROWELL, R. GORDON and M. F. SMITH \\ Department of Physics and Astronomy, University College London, Gower Street, London WC1E 6BT, U.K. \\ N. C. MAYNARD \\ Space Science Division, Air Force Geophysics Laboratory/PHE, Hanscom AFB, MA 01731, U.S.A.
}

J. P. HEPPNER, N. W. SPENCER and L. WHARTON

Goddard Space Flight Center, Greenbelt, MD 20771, U.S.A.

and

P. B. HAYS and T. L. KILLEEN

Space Physics Research Laboratory, University of Michigan, Ann Arbor, MI 482109, U.S.A.

(Received 20 May 1985)

\begin{abstract}
The strength and direction of the Interplanetary Magnetic Field (IMF) controls the transfer of solar wind momentum and energy to the high latitude thermosphere in a direct fashion. The sense of " $Y$ " component of the IMF $(B Y)$ creates a significant asymmetry of the magnetospheric convection pattern as mapped onto the high latitude thermosphere and ionosphere. The resulting response of the polar thermospheric winds during periods when $B Y$ is either positive or negative is quite distinct, with pronounced changes in the relative strength of thermospheric winds in the dusk-dawn parts of the polar cap and in the dawn part of the auroral oval. In a study of four periods when there was a clear signature of $B Y$, observed by the ISEE-3 satellite, with observations of polar winds and electric fields from the Dynamics Explorer-2 satellite and with wind observations by a ground-based Fabry-Perot interferometer located in Kiruna, Northern Sweden, it is possible to explain features of the high latitude thermospheric circulation using three dimensional global models including BY dependent, asymmetric, polar convection fields. Ground-based Fabry-Perot interferometers often observe anomalously low zonal wind velocities in the (Northern) dawn auroral oval during perinds of extremely high geomagnetic activity when $B Y$ is positive. Conversely, for $B Y$ negative, there is an early transition from westward to southward and eastward winds in the evening auroral oval (excluding the effects of auroral substorms), and extremely large eastward (sunward) winds may be driven in the auroral oval after magnetic midnight. These observations are matched by the observation of strong anti-sunward polar-cap wind jets from the $D E-2$ satellite, on the dusk side with $B Y$ negative, and on the dawn side with $B Y$ positive.
\end{abstract}

\section{INTRODUCTION}

A number of empirical studies during the past decade have highlighted the dynamical effects of the ion convection patterns generated by the solar wind and magnetosphere interaction on the wind systems of the thermosphere in the polar regions. Rees $(1971,1973)$ showed that in the vicinity of the auroral oval, zonal winds could be related to the ion drag momentum coupling. This process generates zonal winds which are basically westward in the evening auroral oval, driven by a northward electric field, and eastward in the morning auroral oval, driven by a southward electric field. The magnitude of the zonal winds was found to increase when the auroral electrojets were locally enhanced.

The satellite observations of DeVries (1972), later rocket-borne chemical release observations by Meriwether et al. (1973) and Kelley et al. (1977), and ground-based Fabry-Perot observations by Nagy et al. (1974) and by I Iays et al.(1979) demonstrated that high velocity winds, considerably in excess of the 100 $200 \mathrm{~m} \mathrm{~s}^{-1}$ to be expected from winds generated solely by solar e.u.v. heating, were common in the vicinity of the auroral oval and polar cap. Moreover, in the auroral oval, many of the high velocity winds observed were directed sunward (in the evening auroral oval in particular), quite contrary to the sense of winds 
generated by a solar e.u.v.driven source. Since 1976, a number of other sources of data on high latitude wind distributions have been published, including Pereira $e t$ al. (1980), Smith and Sweeney (1980), Hernandez and Roble (1978), Rees et al. (1980), Mikkelson et al. (1981) and Heppner and Miller (1982). The launch of the Dynamics Explorer (DE) satellites in 1981 (Hoffman and Schmerling, 1982) provided a new impetus to empirical and theoretical studies of the thermosphere, and in particular to studies of the response of the polar regions to geomagnetic activity. The Fabry Perot interferometer (FPI) (Hays et al., 1981), and the Wind and Temperature sensor(WATS)(Spencer et al., 1981), provided separate measurements of the meridional and zonal wind respectively, which could be combined (Killeen et al., 1982) to give a vector neutral wind measurement over a complete perigee pass of the polarorbiting satellite $(D E-2)$ for the height range 320 $350 \mathrm{~km}$ (approx.).

The global thermospheric models (e.g. Rees et al., 1983 and Roble et al., 1983) have used symmetric models of the polar ion convection patterns from Heppner (1977) and Volland (1978) as a basis for describing the ion drag momentum source at high latitudes. That is, the convection pattern is aligned with the sun/earth direction in a geomagnetic frame of reference, and the potential drop across the dusk and dawn parts of the auroral oval and polar cap are approximately equal. This symmetry, to some extent, also will appear in the high latitude energy input particularly if the semi-empirical Chiu (1975) plasma density model is used to describe the global ionosphere.

If thermospheric wind data obtained by $D E-2$ from single orbits, or from ground-based Fabry-Perot interferometers (GBFPI) on a single night, are considered it becomes clear that for a significant fraction of these data sets, successful modelling is not possible if the polar convection electric field is constrained to be symmetric. That is, simulation of the thermospheric wind distribution observed during an entire perigee pass over the high latitude regions (from $D E-2$ ), or for the duration of an entire night (from the GBFPI), would require unrealistic plasma densities or non-physical sources of geomagnetic energy if the convective ion velocity was everywhere scaled to a symmetric pattern.

For example, the satellite instruments have frequently observed strong anti-sunward wind jets over the geomagnetic polar cap which may be located near either the dusk or dawn boundaries between the polar cap and the auroral oval, rather than being located symmetrically across the centre of the polar cap (Hays et al., 1984). Observations from a GBFPI located in northern Scandinavia (Rees et al., 1982, 1983a,b,c) have shown that at different times of comparable geomagnetic activity (at moderate to high activity levels), there are occasions when thermospheric winds throughout the dawn auroral oval may either be anomalously strong, or almost absent. The same GBFPI data base has also shown that the time of transition from the strong westward winds associated with the dusk auroral oval, to the strong equatorward (anti-sunward) winds of the magnetic midnight and postmidnight regions, may vary by several hours.

The clearest instances of the anomalies in either the satellite or the ground-based data (by contrast with the predictions from model simulations using symmetric convection models, or average data) appear to have occurred when, during the preceding period, the " $Y$ " component of the Interplanetary Magnetic Field $(B Y)$ was systematically either positive or negative, for a period of several hours.

Semi-empirical models of the polar electric field distributions have been prepared for the situations where $B Y$ is systematically positive (the $B 2$ field) or systematically negative (the $\mathrm{A} 2$ field) by Heppner and Maynard (1983). These characteristic field models have been introduced into the UCL 3D-TD global model to investigate the changes in high latitude thermospheric winds which may be associated with the sense of the " $Y$ " component of the IMF. Comparisons of the new model simulations with the $D E-2$ and GBFPI neutral wind observations show that the asymmetric models help to resolve many of the features observed in the data.

The present study is incomplete; there is, as yet, no complementary study of the patterns of magnetospheric energetic plasma precipitation as a function of the " $Y$ " component of the IMF. A necessary follow-on study would be the inclusion of precipitation patterns with a dependence on the " $Y$ " component of the IMF in a self-consistent way, reflecting the ionisation and heating effects of the precipitation, and the combined effects of electric fields and neutral winds in redistributing ionization.

\section{THE POLAR ION CONVECTION DISTRIBUTION}

A number of semi-empirical or theoretical models of the convective electric field over the polar and auroral region have been presented including Heppner (1977), Volland (1978), Spiro et al. (1978), Heelis et al. (1982). In the main, these models have a relatively symmetric distribution of electric potential over the polar cap. Spiro's model does have a considerable asymmetry between the magnitude of the electric field potential drop across the dusk and dawn parts of the auroral oval, and Heppner (1977) introduces two asymmetric 
models of convection $(A, B)$ (based on $060-6$ data) which he suggests may be related to the " $Y$ " component of the IMF.

Recently, and based on the wide distribution of data obtained from the Dynamics Explorer-2 satellite, Heppner and Maynard (1983) have delineated changes of the polar cap ion convection pattern correlated with the sense of the " $Y$ " component of the IMF. The two convection distributions are shown in Figs. 1 and 2 , corresponding to the ion convection in the Northern Hemisphere for $B Y$ positive (B2 Model) and for $B Y$ negative (A2 Model) respectively. The convection pattern in the Southern Hemisphere for $B Y$ positive would be that for the Northern Hemisphere with $B Y$ negative. Similarly, for the Southern Hemisphere the distribution for $B Y$ negative would be the same as that in the Northern Hemisphere with $B Y$ positive. The major differences to be inferred from the response of the convection pattern to the sense of the " $Y$ " component of the IMF are summarized in Table 1.

Unambiguous signatures in the ion convections pattern will only be established if the entire magnetosphere is immersed within a relatively homogeneous region of the solar wind for a period of a few hours. This will establish consistent boundary conditions over a large part of the surface of the magnetosphere, including its extension to considerable distances down the magnetospheric tail.

The use of these patterns in global modelling of the thermospheric response is limited because, as yet, no empirical models of the high latitude magnetospheric precipitation, sorted in a comprehensive way by $B Y$ positive and $B Y$ negative, have been created. It is thus not yet possible to create a fully realistic empirical description of all of the parameters involved in modelling the thermospheric consequences of the response to the sense of the " $Y$ " component of the IMF.

\section{THE THREE-DIMENSIONAL AND TIME-DEPENDENT GLOBAL THERMOSPHERIC MODEL.}

The formulation and characteristics of the University College London (UCL) three-dimensional, time-dependent (3-D, T-D) global thermospheric model have been described in a series of papers (Rees $e t$ al., 1980; Fuller-Rowell and Rees, 1980, 1981, 1983, 1984). In some of these papers and others (Rees et al,

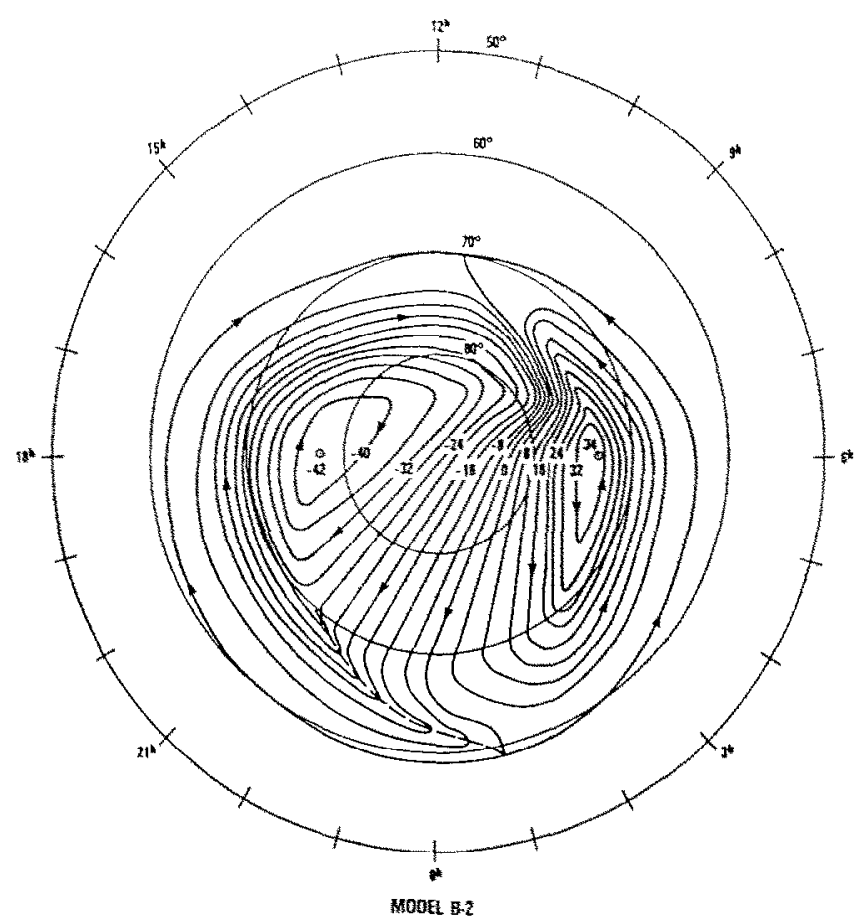

Fig. 1. The B-2 POLAR CONVECTION ELECTRIC POTENTIL DISTRIBUTION (From HEPPNER AND MaYNARD, 1983). Used in the Northern Hemisphere when the " $Y$ " component of the IMF is positive, and in the Southern Hemisphere when the " $Y$ " component of the IMF is negative. 


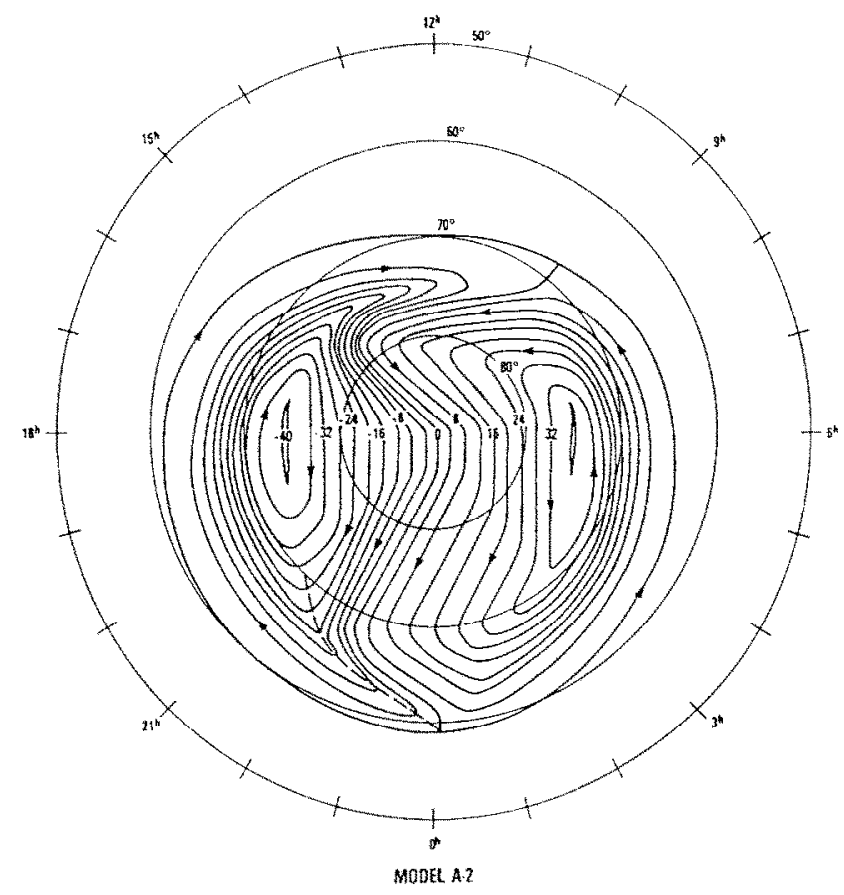

Fig. 2. The A-2 polar CONvection electric Potential distribution (From Heppner and Maynard, 1983). Used in the Northern Hemisphere when the " $y$ " component of the IMF is negative, and in the Southern Hemisphere when the " $Y$ " component of the IMF is positive.

Table 1

\begin{tabular}{|c|c|}
\hline$B Y+v e$ & $B Y-v e$ \\
\hline $\begin{array}{l}\text { Main convection entry to polar cap } \\
\text { about } 09 \text { L.M.T. }\end{array}$ & $\begin{array}{l}\text { Main convection entry to polar cap } \\
\text { about } 15 \text { L.M.T. }\end{array}$ \\
\hline $\begin{array}{l}\text { Strong potential gradient (dusk-dawn) } \\
\text { on dawn side of polar cap }\end{array}$ & $\begin{array}{l}\text { Strong potential gradient (dusk- } \\
\text { dawn) on dusk side of polar cap }\end{array}$ \\
\hline $\begin{array}{l}\text { Dusk polar cap is a broad, low } \\
\text { velocity region }\end{array}$ & $\begin{array}{l}\text { Dawn polar cap is a broad, low } \\
\text { velocity region }\end{array}$ \\
\hline $\begin{array}{l}\text { Dusk auroral oval convection } \\
\text { continues westward to } 09 \text { L.M.T. }\end{array}$ & $\begin{array}{l}\text { Dusk auroral and westward convection } \\
\text { curtailed at } \sim 14 \text { L.M.T. }\end{array}$ \\
\hline $\begin{array}{l}\text { Dusk auroral oval westward convection } \\
\text { extends to 01 L.M.T. }\end{array}$ & $\begin{array}{l}\text { Dusk auroral oval westward } \\
\text { convection starts at } 00 \text { L.M.T. }\end{array}$ \\
\hline $\begin{array}{l}\text { Dawn auroral oval sunward (eastward) } \\
\text { cell curtailed 02-09 L.M.T. }\end{array}$ & $\begin{array}{l}\text { Dawn auroral oval eastward cell } \\
\text { extended } 01 \text { L.M.T. }->14 \text { L.M.T. }\end{array}$ \\
\hline Cross-polar cap potential $76 \mathrm{kV}$ & Cross-polar cap potential $76 \mathrm{kV}$ \\
\hline Potential of dusk boundary $-42 \mathrm{kV}$ & Potential of dusk boundary $-40 \mathrm{kV}$ \\
\hline Potential of dawn boundary $34 \mathrm{kV}$ & Potential of dawn boundary $36 \mathrm{kV}$ \\
\hline Cusp entry to polar cap 11.5 L.M.T. & Cusp entry to polar cap 10 L.M.T. \\
\hline $\begin{array}{l}\text { Harang discontinuity at centre of } \\
\text { auroral oval 01 L.M.T. }\end{array}$ & $\begin{array}{l}\text { Harang discontinuity at centre of } \\
\text { auroral oval } 00 \text { L.M.T. }\end{array}$ \\
\hline $\begin{array}{l}\text { Diameter of polar cap } 28 \\
\text { (degrees geomagnetic latitude) }\end{array}$ & $\begin{array}{l}\text { Diameter of polar cap } 32 \\
\text { (degrees geomagnetic latitude) }\end{array}$ \\
\hline $\begin{array}{l}\text { Diameter of auroral oval } 40 \\
\text { (fastest sunward convection) }\end{array}$ & $\begin{array}{l}\text { Diameter of auroral oval } 42 \\
\text { (fastest sunward convection) }\end{array}$ \\
\hline
\end{tabular}


1981, 1982a, b, 1983c,d; Heppner and Miller, 1982; King-Hele and Walker, 1983), recent empirical thermospheric data from a variety of rocket, satellite and ground-based techniques have been compared with model simulations for a suitable geophysical situation, including the variable effects of season, solar and geomagnetic activity.

One of the most important physical processes driving the thermospheric response to a particular level of geomagnetic activity is the polar ion convection distribution driven by the magnetospheric electric field.

The UCL 3D-TD model has been used to examine the different effects of a number of semi-empirical or theoretical models of the polar convection electric field. Early versions (Rees et al., 1980, 1983a,b,c) used symmetric convection models based on the work of Heppner (1977) and Volland (1978). The later work described by Quegan et al. (1982) and Fuller-Rowell et al. (1984) used the somewhat asymmetric model of Spiro (1978) (with no dependence on the IMF), and was of particular interest as it was used to evaluate the consequences of combining the important interactive effects of precipitation, convection and induced thermospheric winds on the polar ionosphere.

For the purposes of evaluating the effects of the asymmetric polar convection electric fields due to Heppner and Maynard (1983) on the polar thermospheric circulation, a sequence of model simulations has been prepared. All of the simulations have been generated for the solar activity and seasonal conditions appropriate for the period mid-November 1981 to early February 1982 (Table 2). The conditions are approximately those of the Northern Hemisphere winter solstice, since the thermospheric wind changes induced by the small variation of solar illumination alone through this period are quite small compared with the effects induced by variable geomagnetic activity.
Two ionospheric models have been used with each of the polar electric field situations, providing a range of four simulations. Two of these simulations $(I 2$, JA) correspond to moderately quiet geomagnetic conditions, and the other two (JB, JC) correspond to moderately disturbed conditions. In the JB and JC models, soft electron sources have been introduced into the polar cap and the polar cusp regions. Rees et al. (1985a) have compared the mean thermospheric wind patterns obtained from the $D E-2$ satellite in both the North and the South Hemispheres with these theoretical simulations. In one final simulation(JQ), for $B Y$ positive only, auroral electrons as described by Spiro et al. (1982) have been added to the input of the JC model. This has the effect of enhancing plasma density, ion drag and frictional heating within the auroral oval. In the $B Y$ positive simulations (JA, JC, JQ) the driving convection patterns are $B 2$ in the Northern Hemisphere and $A 2$ in the Southern Hemisphere. For the $B Y$ negative simulations $(\mathrm{J} 2, \mathrm{JB})$ the $\mathrm{A} 2$ pattern is used in the Northern Hemisphere and the $B 2$ pattern is used in the Southern Hemisphere. The simulations used in this paper are summarized in Table 3.

The Chiu ionospheric model reflects no enhancement of the polar ionosphere due to any geomagnetic processes. When the Chiu ionosphere is combined with the A2 or B2 polar convection field models, the resulting model simulates moderately quiet geomagnetic conditions $\left(K_{p} 2\right)$ by a combination of rather overestimating the convection field and under-estimating the enhancement of ionospheric plasma densities, particularly in the winter polar region, due to geomagnetic processes.

The PIONS polar ionosphere model can use, as input, a theoretical description of the magnetospheric particle precipitation, or an empirical model such as that of Spiro et al. (1982). As a result, the polar ionospheric plasma densities will be enhanced by

TABLe 2.

$\begin{array}{ll}\text { 1/2 December 1981: } & B Y-\text { ve before } 15 \text { U.T.; } B Y+\text { ve after 15 U.T. } \\ & B Z \text { variable southward and northward periods. } \\ & B \text { mainly about 5-10 nT. } \\ \text { 6/7 December 1981: } & B Y \text { positive throughout. } \\ & B Z \text { southward, 2-5 nT. } \\ & B \text { about } 5 \mathrm{nT} . \\ & B Y \text { negative until 05 U.T. on 26 December. } \\ \text { 25/26 December 1981: } & B Z \text { mainly southward, but small values. } \\ & B 4-6 \text { nT. } \\ & B Y-\text { ve. EX 18-21 U.T. } \\ & B Z-\text { ve. 17-22 U.T. and 0 U.T. }-> \\ \text { 12/13 February 1982: } & B>20 \text { U.T. < 22 U.T. to } 15 \text { nT at 08 U.T. }\end{array}$


magnetospheric particle precipitation. The threedimensional polar ionosphere is treated as a series of one-dimensional solutions, based on the work of Roble and Rees (1977), where the effects of plasma transport and interactions between the ionosphere and thermosphere are ignored. The heat input due to these particles is included in the neutral energy equation.

This approach, its usefulness and its limitations, has been discussed in some detail by Smith (1984) and by Rees et al. (1985a). When the A2 or the B2 polar convection field is used with the PIONS polar ionospheric model, and the soft electrons in the polar cap and polar cusp region are added (Table 2), the resulting model is considered to reflect moderately disturbed geomagnetic conditions, where $K_{p}$ would be between 3 and about 4 (Rees et al., 1985a).

When auroral electrons (Spiro et al., 1982) for $100<A E<300$ are added, as well as the soft polar cap electrons, the resulting simulation is considered to be representative of conditions where $K_{p}$ would be in the range between 4 and about 6 . Note that all of the simulations used here only have U, T -dependence, and that there is no attempt to simulate the individual large substorms which would punctuate periods of moderately disturbed geomagnetic activity.

The model results are available at a total of 15 pressure levels between 80 and approx. $500 \mathrm{~km}$, and for all Universal Times for the northern winter/southern summer solstice which have been chosen for these simulations. For illustration, the instantaneous wind distributions at a constant altitude of $320 \mathrm{~km}$ for the $\mathrm{JB}$ and $\mathrm{JC}$ simulations have been presented for two Universal Times: 18 U.T.; (Fig. 3, Northern Hemisphere; Fig. 4, Southern Hemisphere), and 2.4 U.T.; (Fig. 5, Northern Hemisphere, Fig. 6, Southern Hemisphere).

These figures are snapshots of the circulation in both the North and South polar regions and show, at these Universal Times, the corresponding wind flows produced by the convective electric field for situation where the " $Y$ " component of the IMF is systematically either positive (JC) or negative (JB). In an alternative presentation, the simulated global data (comprising the "snapshots" at $1.2 \mathrm{~h}$ U.T. intervals) have been sampled to show meridional profiles for the L.T. plane 06-18 L.S.T., as a function of Universal Time (1.2-h intervals) for comparison with the data base acquired from the neutral wind measuring instruments of the $D E-2$ satellite during December 1981 (Hays et al., 1984). Figure 7 shows the JC simulation for the Northern Hemisphere ( $B Y$ positive, moderately disturbed), while Fig. 8 shows the complementary (JB) simulation. In Fig. 9 , the JQ simulation, for more disturbed geomagnetic conditions ( $B Y$ positive) is shown. The increase in the magnitude of sunward winds in the dusk auroral oval, and the tendency for sunward winds in the dawn auroral oval, are the major changes produced by the increased activity (compare Figs. 7 and 9).

The effects on thermospheric circulation at high latitude which result from alternating between a positive or a negative value of the " $Y$ " component of the IMF are qualitatively similar for both ionospheric models (Chiu or PIONS), although the magnitude of the winds in the polar regions are significantly enhanced when the latter jonospheric model is used. The following discussion summarizes the major consequences:

\section{SIMULATION 1. BY NEGATIVE}

(i) Northern Hemisphere-A2 field applied $(\mathrm{J} 2, \mathrm{JB})$

The major effect of applying the A2 field to the Northern Hemisphere is to produce a considerable increase in the equatorward and eastward wind velocities of the post-magnetic midnight region of the Northern Hemisphere auroral oval, relative to those produced with the same ionospheric plasma densities with the symmetric or the $B 2$ electric field patterns (compare Figs. 3B with $3 \mathrm{~A}$ ). A second effect is that there is a complete circulation cell involving the dawn auroral oval and the dusk and central portions of the geomagnetic polar cap. This anticlockwise circulation cell is particularly pronounced during the U.T. period between 16 and 02 U.T. (see Figs. 3B and 5B).

In general, for an auroral oval station, the time of onset of equatorward and eastward winds (following the dusk period of westward winds) occurs at earlier magnetic time. This is associated with a strengthening of the anti-sunward winds in the dusk part of the polar cap (relative to symmetric models, compare Figs. 5B and $5 \mathrm{~A}$ ).

The winds of the dusk auroral oval are not weakened significantly under the influence of the A2 convection model, but the local time region occupied by these westward winds is shortened by 2 or $3 \mathrm{~h}$.

\section{(ii) Southern Hemisphere-B2 field applied (J2, JB)}

The major effects of the B2 field in the Southern Hemisphere are firstly, to induce a strong cyclonic vortex encompassing the dusk auroral oval and the dawn part of the geomagnetic polar cap (Figs. $4 \mathrm{~B}$ and 6B).

Secondly, the sunward winds induced in the dawn auroral oval are considerably weaker than those produced by the $\mathrm{A} 2$ field (compare Figs. $4 \mathrm{~B}$ with $4 \mathrm{~A}$ ). The sunward winds of the dawn auroral oval appear to be disconnected from the polar cap circulation.

The strong anti-sunward winds of the dawn part of 


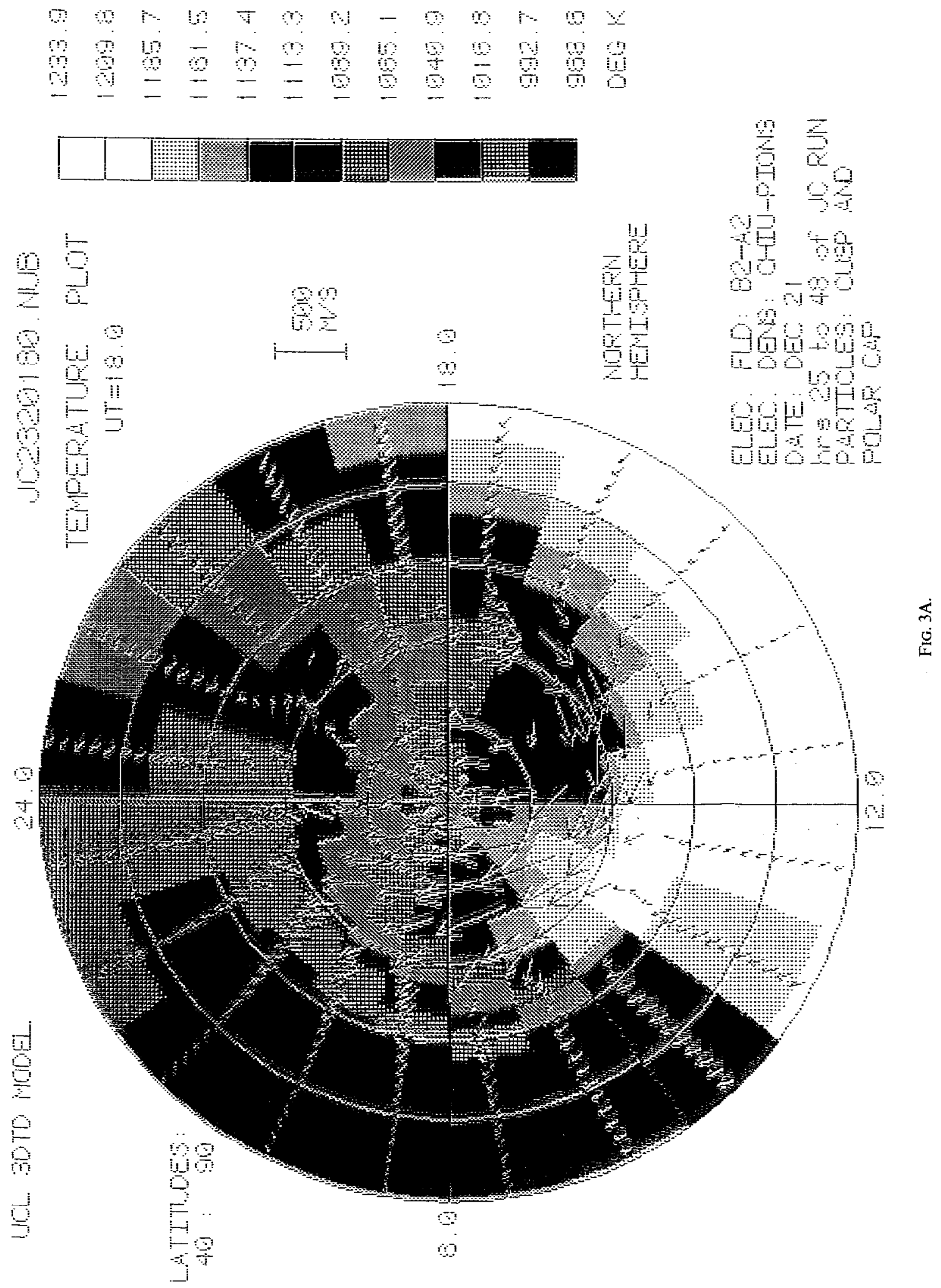




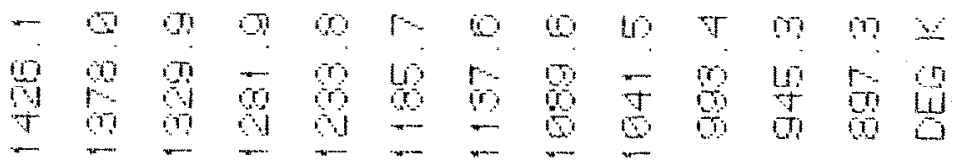

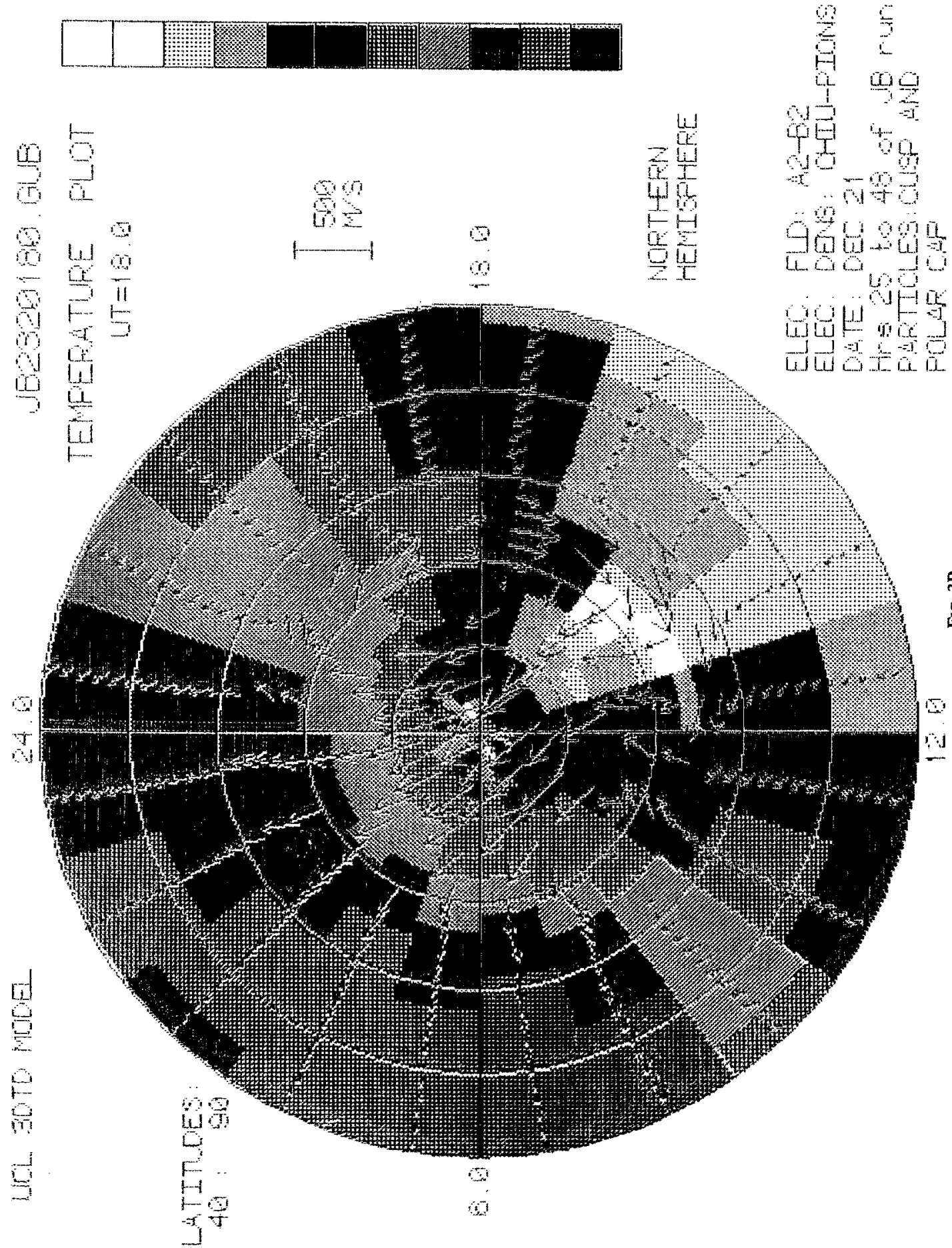




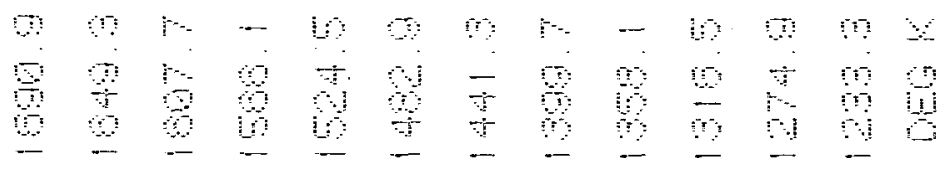

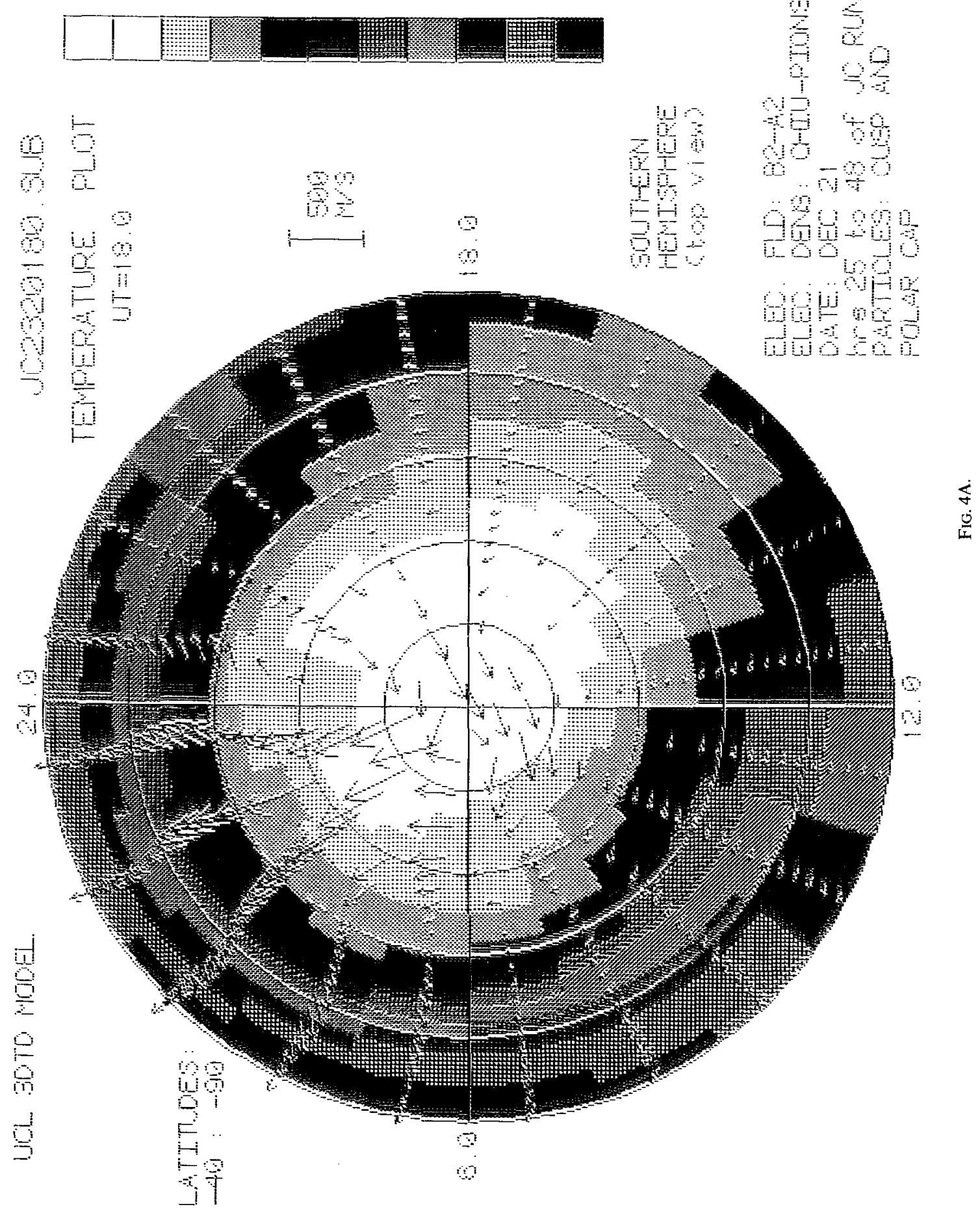



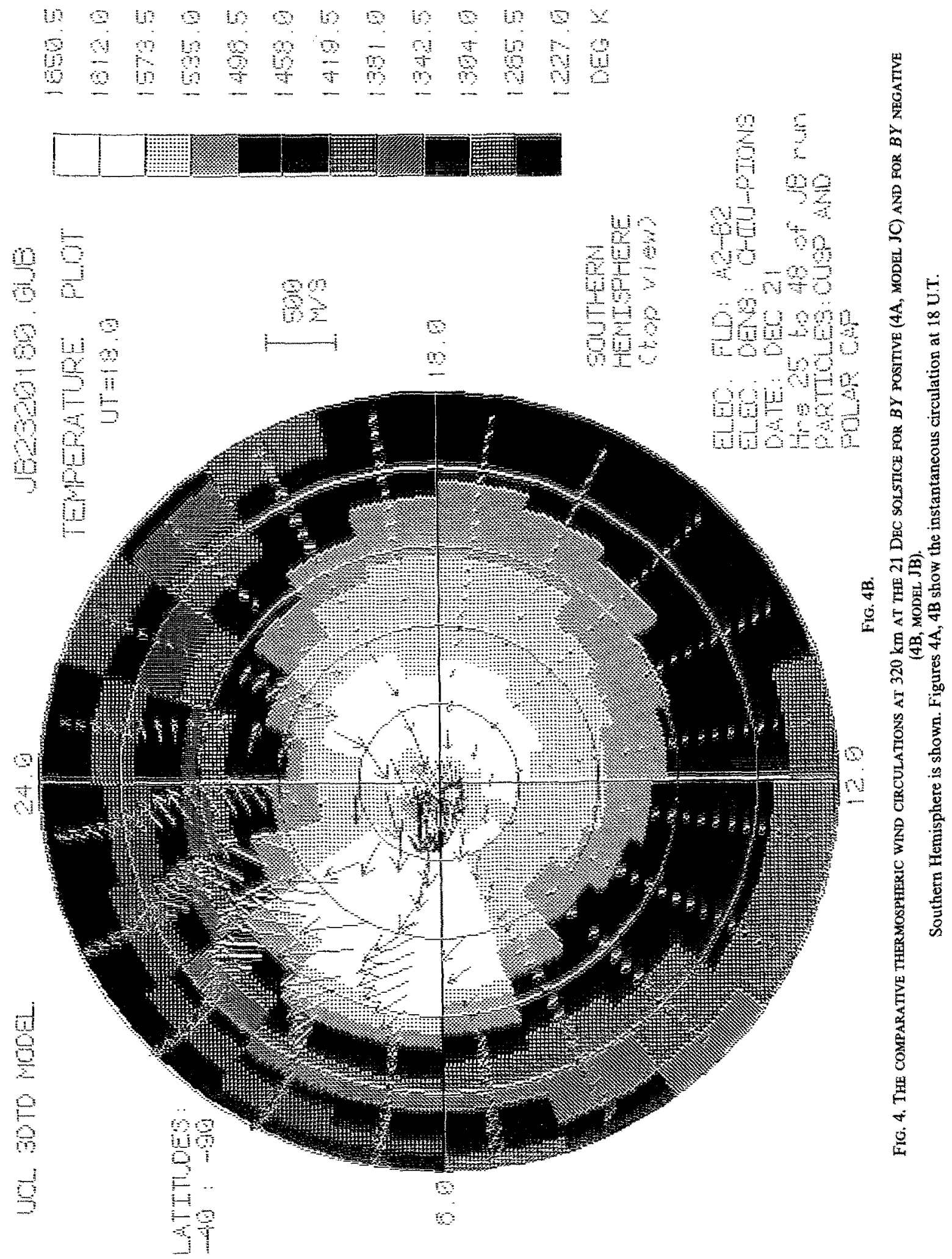


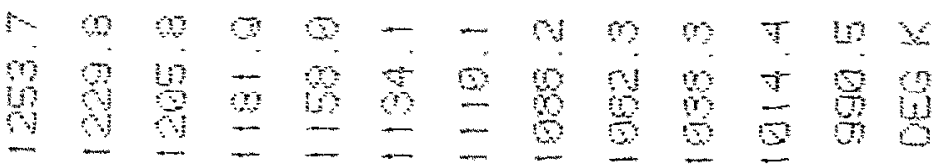

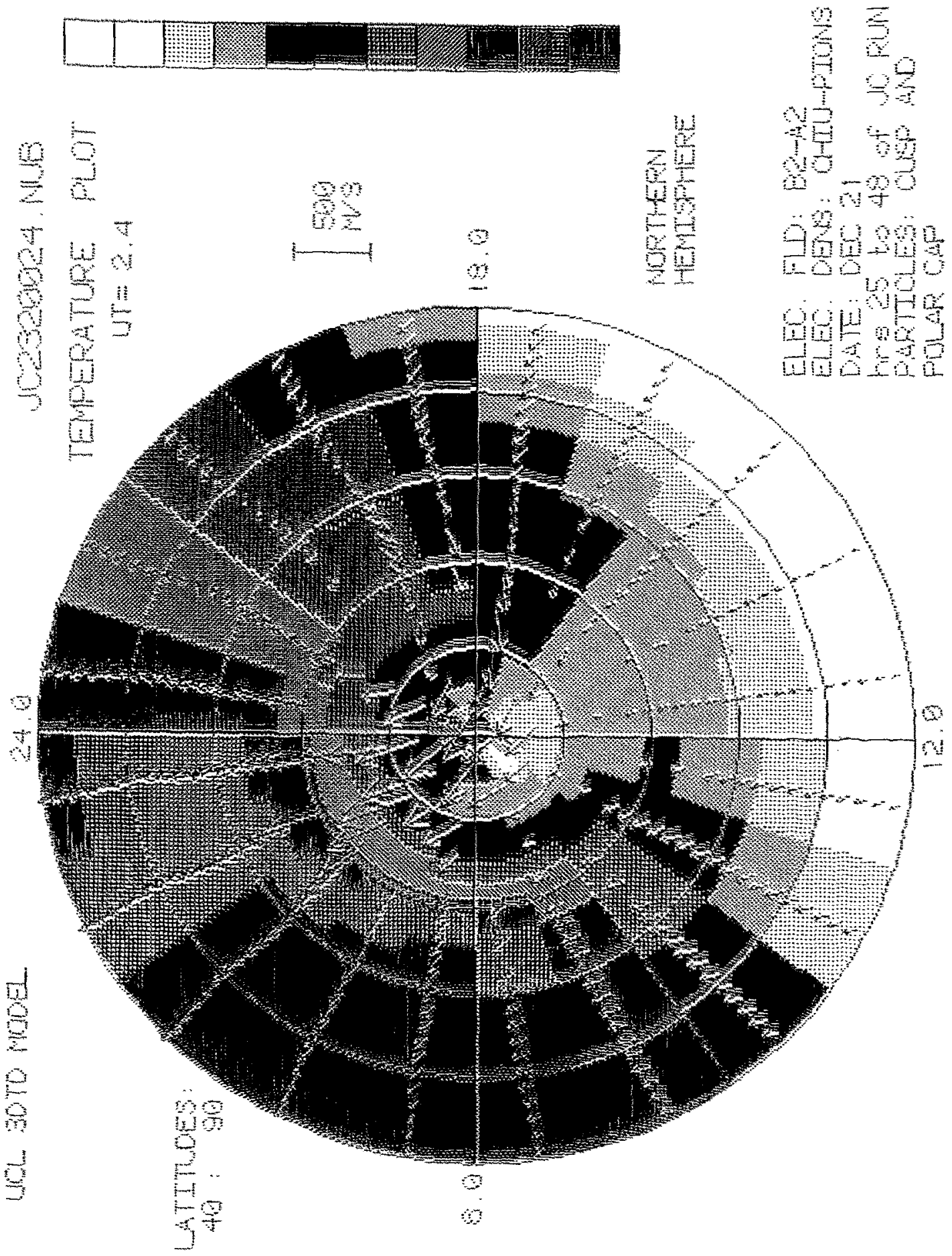




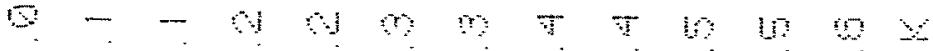

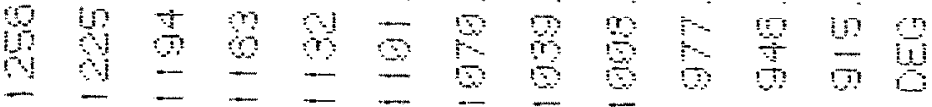

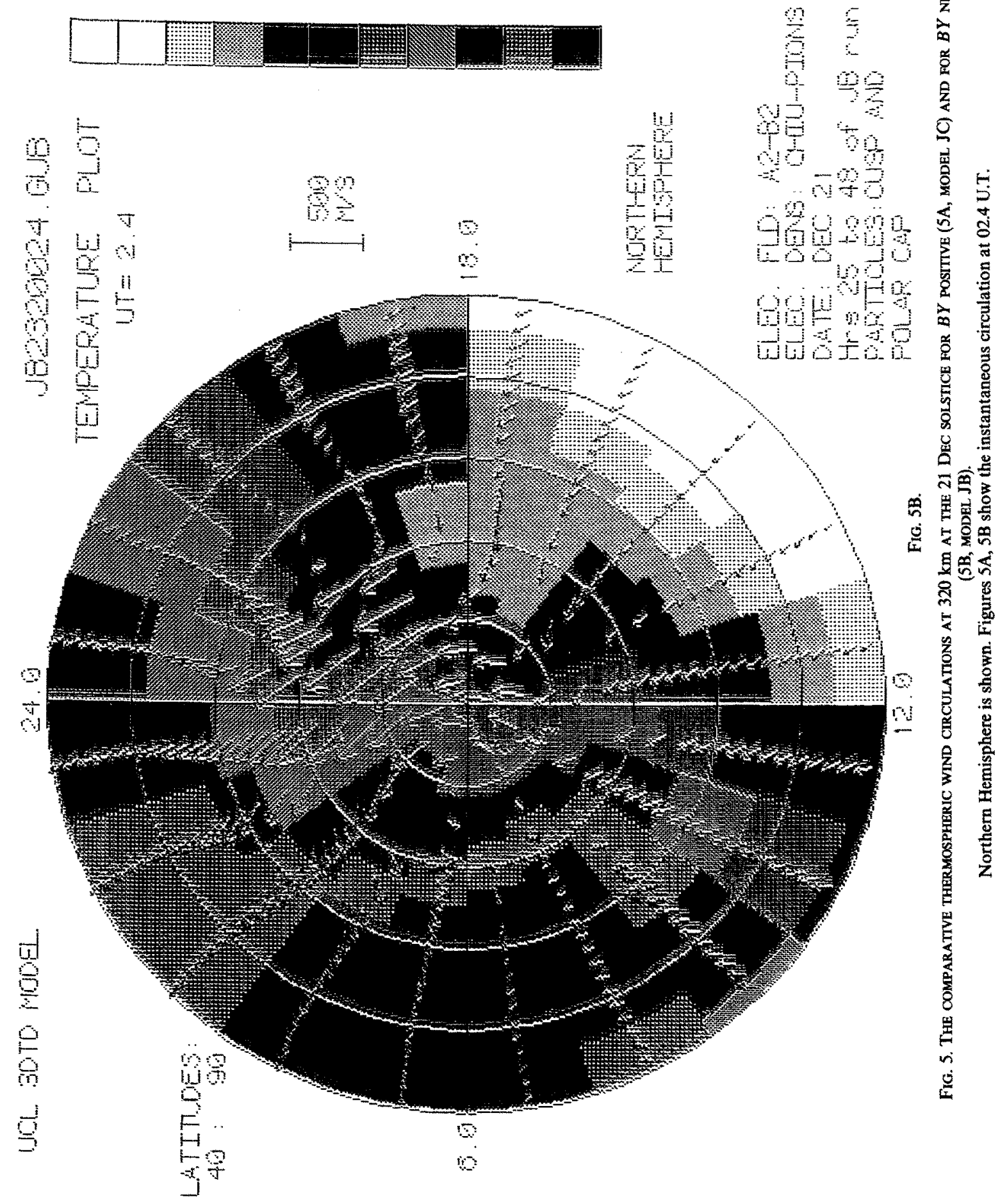




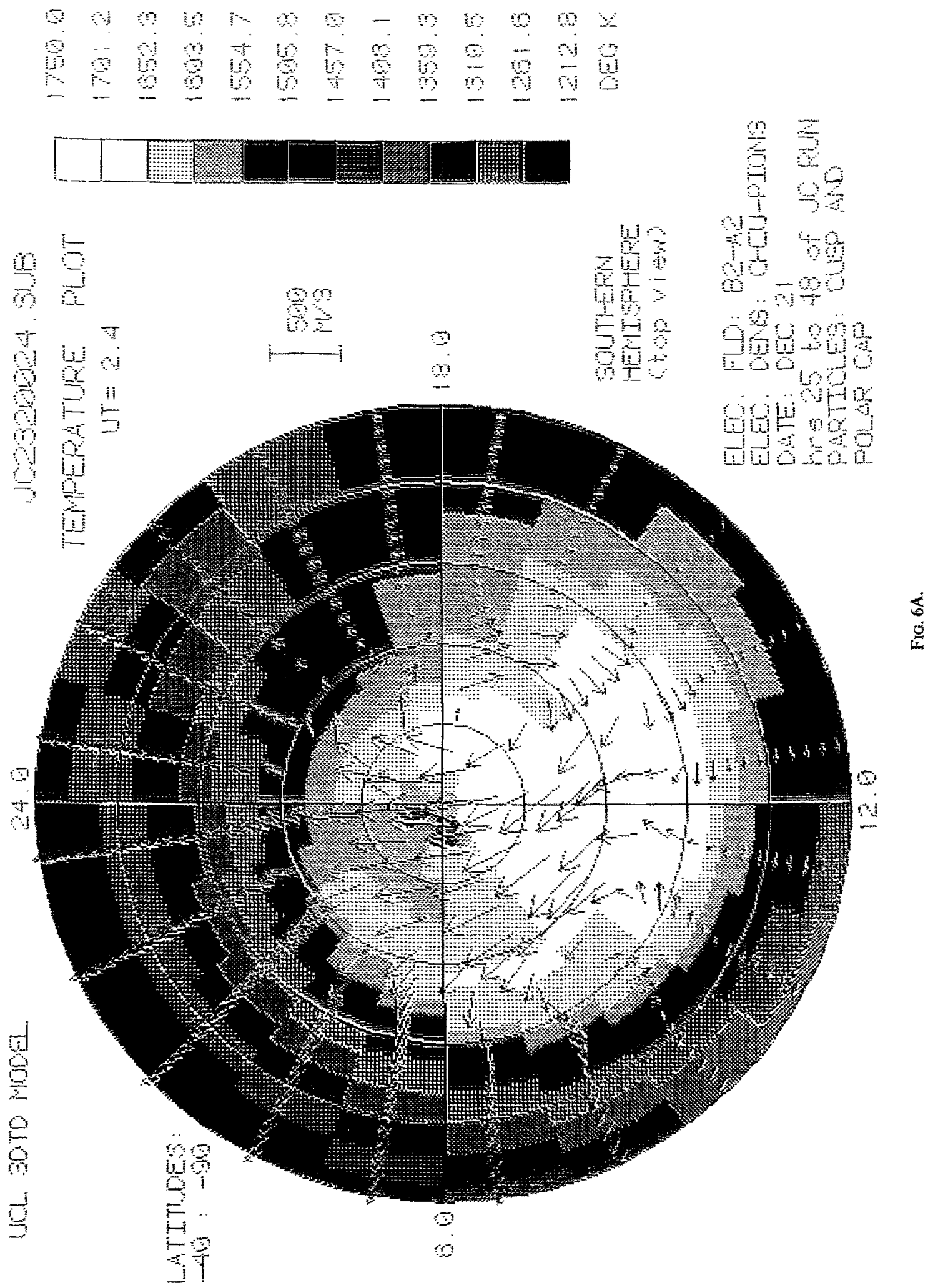




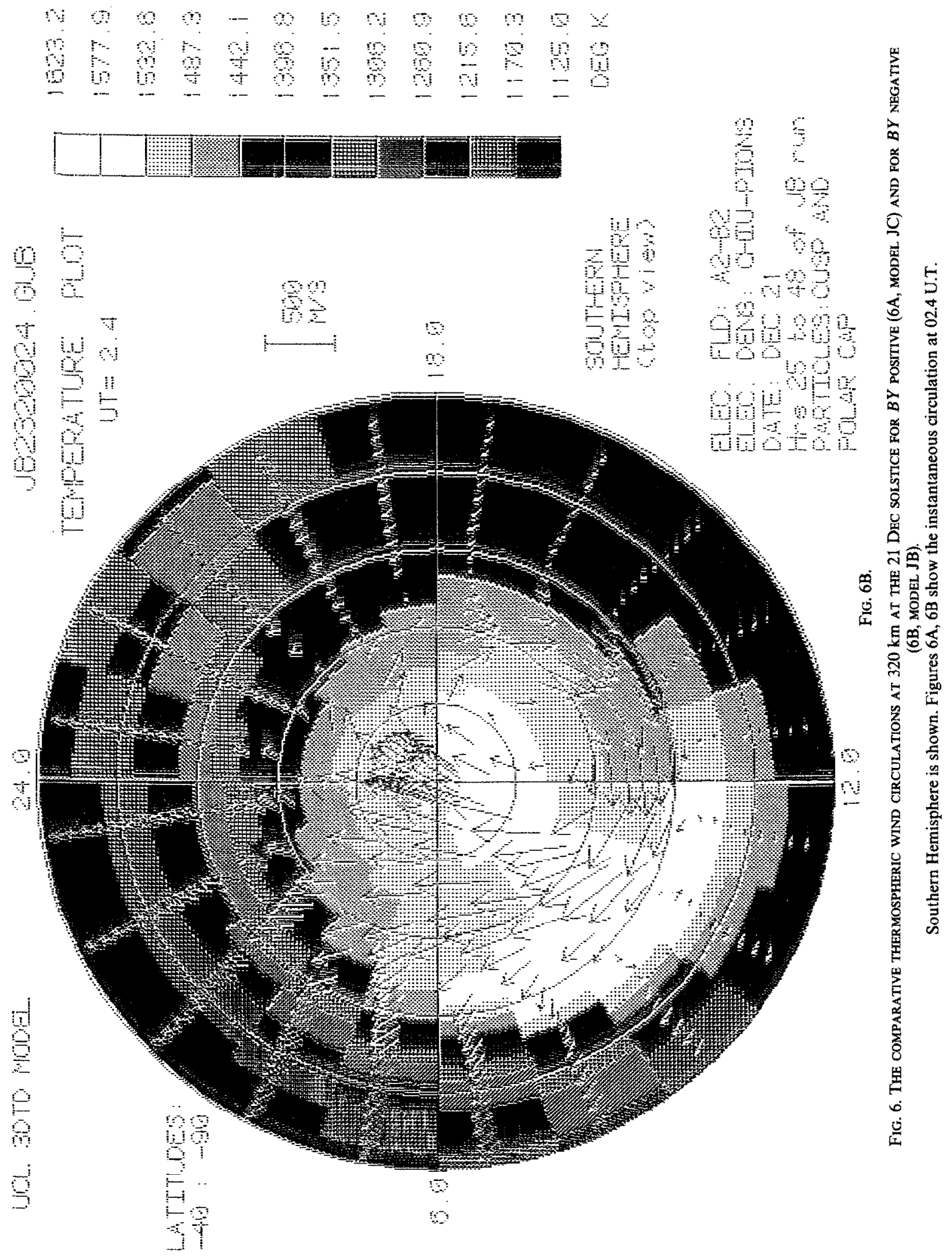


Theoretical and empirical study of the response of the high latitude thermosphere

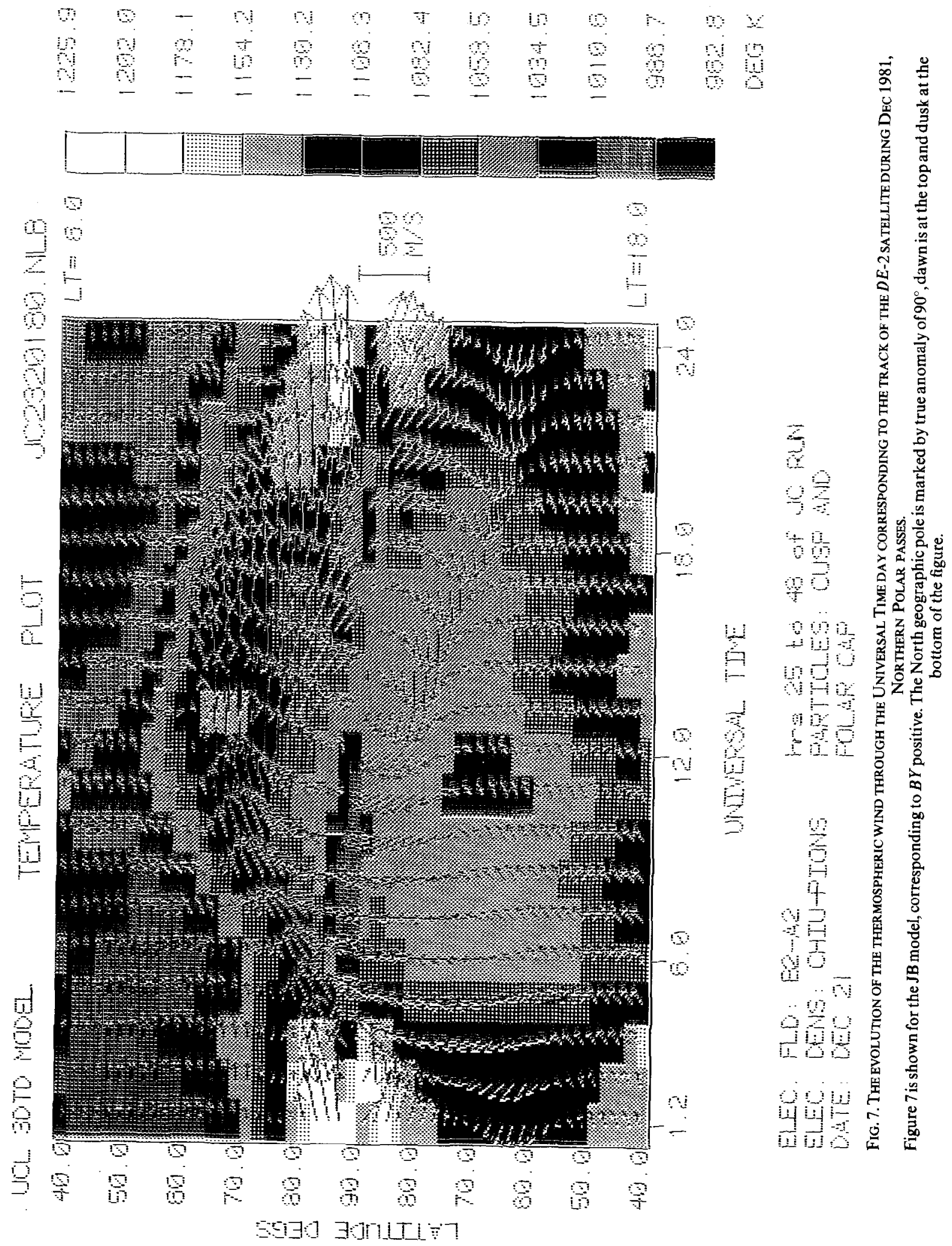




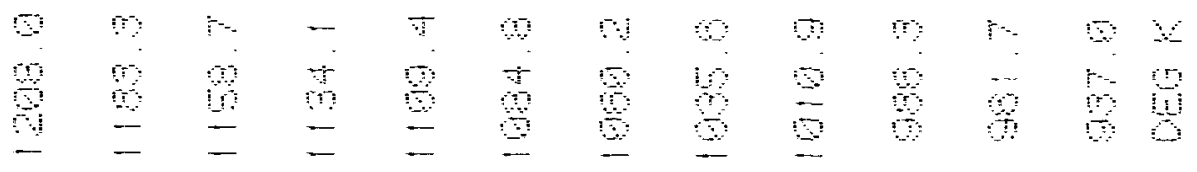
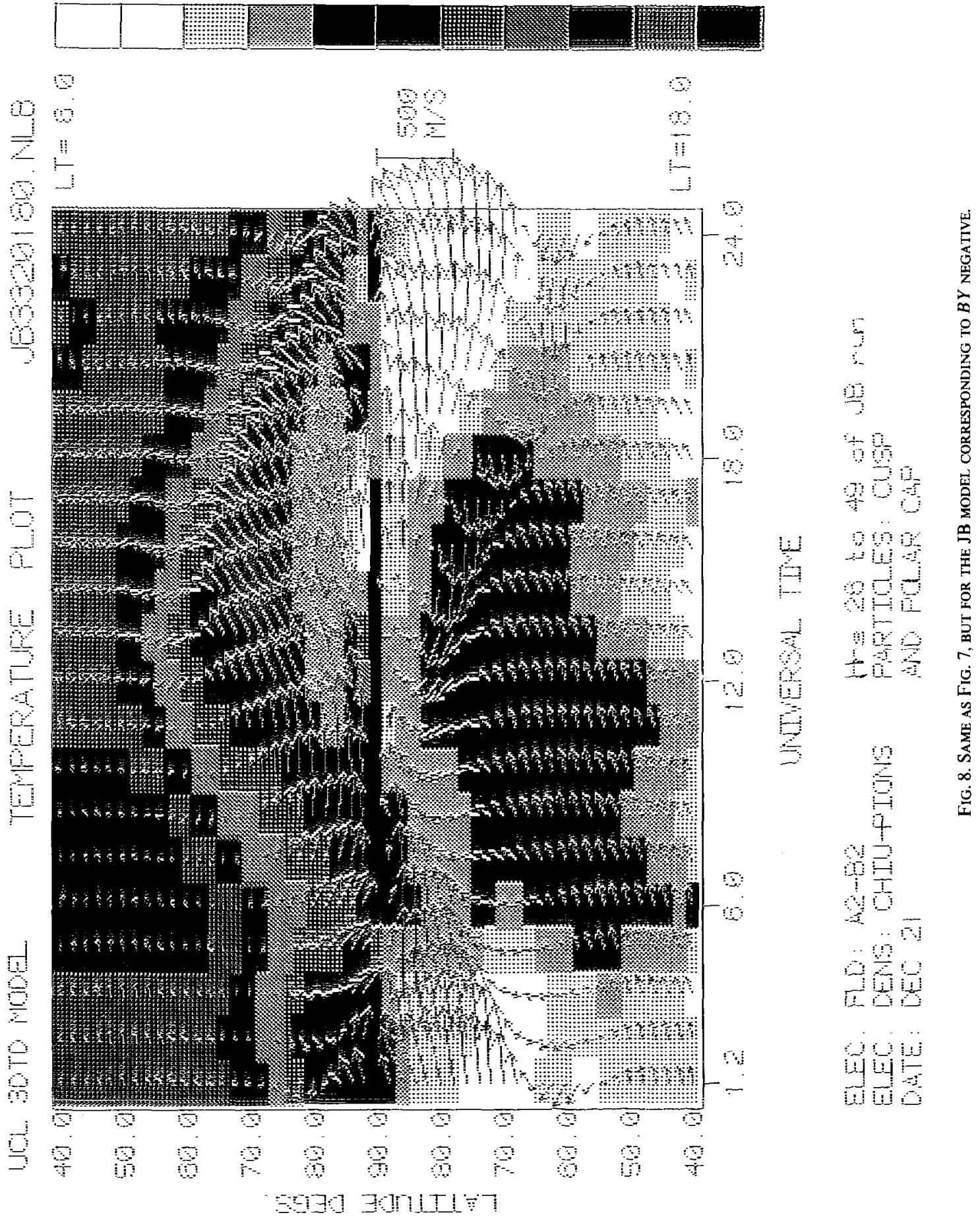
Theoretical and empirical study of the response of the high latitude thermosphere

\begin{tabular}{|c|c|c|c|c|c|c|c|c|c|c|}
\hline 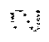 & 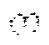 & 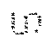 & $i_{m}$ & $\theta$ & $\because$ & 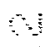 & 4 & 1 & + & 7 \\
\hline$\leftarrow$ & 10 & 0 & 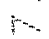 & $\pi$ & 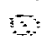 & - & 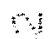 & 4 & $\pi$ & $r$ \\
\hline 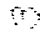 & 3 & $\overbrace{-\infty}^{+\infty}$ & $\rightarrow$ & - & 10 & 0 & 58 & $\vdots$ & $r$ & 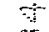 \\
\hline 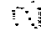 & $=$ & - & - & - & 3 & & $\square$ & 3 & 9 & $a$ \\
\hline- & -. & - & - & - & - & - & - & - & & \\
\hline
\end{tabular}
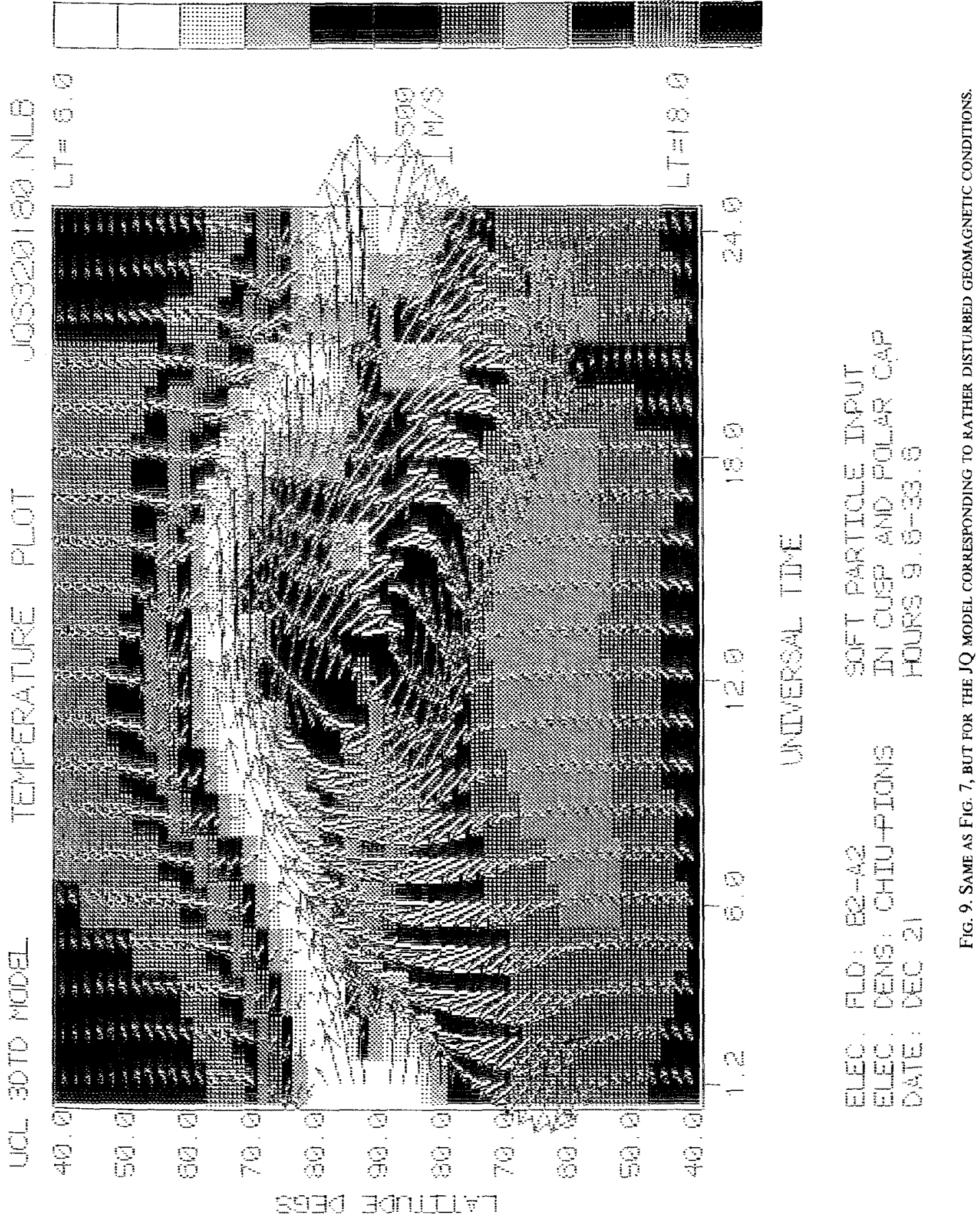

the polar cap connect into a region of strong equatorward winds post-magnetic midnight, in addition to their connection into the cyclonic vortex involving the dusk auroral oval.

\section{SIMULATION 2. BY POSITIVE}

(i) Northern Hemisphere-B2 field applied (JA, JC, JQ)

The induced thermospheric circulation in the Northern Hemisphere with $B Y$ positive is, as expected, very similar to that occurring in the Southern Hemisphere when the IMF BY component is negative.

A strong anti-sunward wind jet occurs on the dawn side of the geomagnetic polar cap, completing the strong clockwise vortex which is completed within the dusk auroral oval (Fig. 3A). Only when the plasma densities within the auroral oval are enhanced (JQ model), are significant sunward (eastward) winds driven in the dawn auroral oval. As would be anticipated, the JQ model, with enhanced auroral precipitation, shows the highest sunward winds in both the dusk and dawn regions of the auroral oval (Fig. 9).

(ii) Southern Hemisphere-A2 field applied (JA, JC, JQ)

This field configuration induces a circulation in the Southern polar region which is complementary to that occurring in the Northern hemisphere when $B Y$ is negative.

There is a general enhancement of post-magnetic midnight winds in the dawn auroral oval (Fig. 4A). The sunward winds in the dawn auroral oval complete an anti-clock wise circulation cell which includes the dusk part of the polar cap.

The transition time for the change between sunward winds in the dusk or evening auroral oval, and eastward and equatorward winds (i.e. the onset of the antisunward winds flowing over the polar cap) is brought to carlicr magnetic local timc. The anti-sunward winds in the dusk region of the polar cap are strengthened.

The duration of the period of westward and sunward winds in the evening auroral oval is shortened, although the magnitude of the sunward winds is not significantly reduced.

\section{THE EMPIRICAL DATA}

Four periods have been selected for this comparative study of thermospheric winds and the predictions of the theoretical model. The selection characteristics are based on the following criteria :

I. Auroral oval winds for all four nights were observed by the GBFPI located at Kiruna, Sweden, with perfect observing conditions.

II. For all four periods, a relatively clear signature of all three components of the IMF is available from the ISEE 3 spacecraft. Either the " $Y$ " component was persistently positive or negative throughout the observing period, or there was a clear switch of direction at one spccific time.

III. The selected periods occurred when sequences of polar perigee passes of the $D E-2$ satellite provided wind data from the FPI and WATS instruments, and/or polar electric field data from the VEFI instrument. These data thus provided additional information via the wind and ion flow structures within the polar cap region, augmenting the ground-based wind data available from the Scandinavian region of the auroral oval.

The geomagnetic conditions for each of the four selected periods are summarized in Table 3.

There are many other periods of similar general behaviour of winds, as observed from Kiruna, which could have been selected from over 400 nights of thermospheric wind observation since 1980. The selected periods show clear signatures in the polar or auroral oval winds, or are the best correlated groundbased and satellite observations. However, they are also characteristic of the polar wind response during many other periods of observation when there was a systematic trend in the " $Y$ " component of the IMF.

TABLE 3.

\begin{tabular}{|c|c|c|c|c|c|c|}
\hline IMF “ $B Y$ " & N.H. & & S.H. & Ionospheric model & Identifie & \\
\hline $\begin{array}{l}B Y \text { positive } \\
B Y \text { positive }\end{array}$ & A2 & 1 & $\mathrm{~B} 2$ & $\begin{array}{l}\text { Chiu (Moderately quiet) } \\
\text { Pions (Moderately disturbed), } \\
\text { (Polar cap and cusp electrons) }\end{array}$ & $\begin{array}{r}\left.K_{p}<2\right) \\
\left.3<K_{p}<4\right)\end{array}$ & $\begin{array}{l}\text { JA } \\
\text { JC }\end{array}$ \\
\hline$B Y$ positive & & & & $\begin{array}{l}\text { Pions (rather disturbed), } \\
\text { (Polar cap and auroral electrons) }\end{array}$ & $\left.4<K_{p}<6\right)$ & JQ \\
\hline $\begin{array}{l}B Y \text { negative } \\
B Y \text { negative }\end{array}$ & $\mathrm{B} 2$ & 1 & $\mathrm{~A} 2$ & $\begin{array}{l}\text { Chiu (Moderately quiet), } \\
\text { Pions (Moderately disturbed), } \\
\text { (Polar cap and cusp electrons) }\end{array}$ & $\begin{array}{r}\left.K_{p}<2\right) \\
\left.3<K_{p}<4\right)\end{array}$ & $\begin{array}{l}\mathrm{J} 2 \\
\mathrm{JB}\end{array}$ \\
\hline
\end{tabular}




\section{PERIOD 1. 1/2 DECEMBER 1981}

BY negative before 15 U.T., positive after 15 U.T.

The ISEE-3 IMF data for this period are shown in Fig. 10. There was a sudden switch of the $B Y$ component at 15 U.T. Prior to 15 U.T., the IMF " $Y$ " component was consistently negative, while after 15 U.T., it was consisistently positive until later on 2 December 1982. The total IMF field increased, between 10 and 15 U.T., from $6 \mathrm{nT}$ to a moderately high value (12 nT), but the $B Z$ component oscillated between southward and northward, and was mainly northward after 17 U.T., limiting the energy and momentum transfer rates from the solar wind to the magnetosphere.

A series of polar passes of $D E-2$ are available for this period. The first, orbit 1778 , occurred immediately before the $B Y$ component switched sense from negative to positive at 15 U.T. The second, 1779, occurred soon after the change, but probably before the magnetospheric convection had fully responded to the change in IMF $B Y$. The thermospheric winds would respond to the change of polar convection with a further delay of the order of an hour. Orbits 1781 and 1782 occurred during the subsequent extended period when $B Y$ was strongly positive. The polar electric field data from the VEFI instrument on $D E-2$ for these four and three subsequent passes are shown in Fig. 11, corresponding

ISEE-3 INTERPLANETARY MAGNETIC FIELD 1981 DAY 335 I,S COORDS 5 M AVG DAY 336

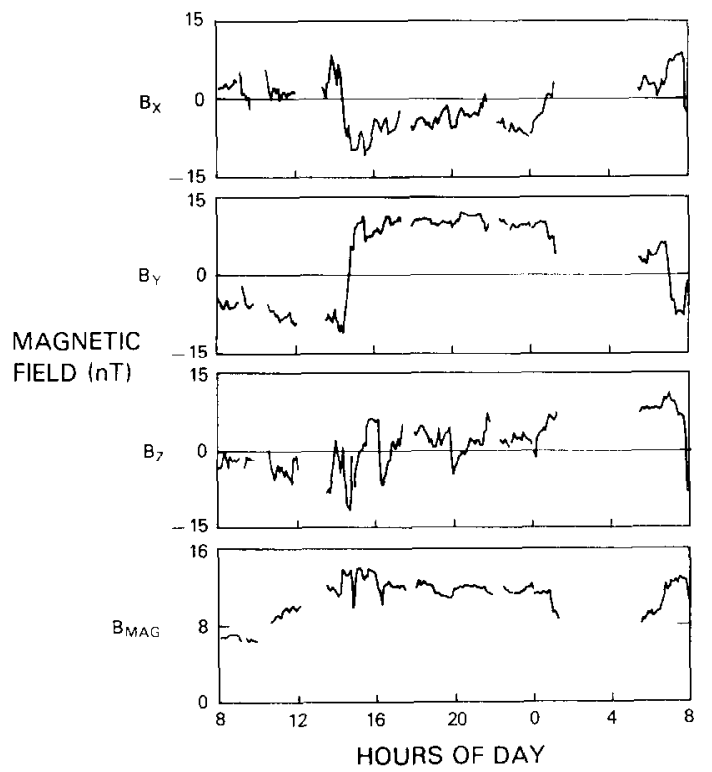

FIG. 10. The IMF AS OBSERVEd BY THE ISEE-3 SATELLITE DURING 1 DEC/2 DEC 1981. to the evolution of the Northern Hemisphere polar electric field during the period from 14 U.T., $(1 \mathrm{Dec})$ until 03 U.T. (2 Dec). At 14:04 U.T., the main antisunward flow was concentrated on the dusk side of the polar cap. The next orbit showed a relatively symmetric pattern across the polar cap. By orbit 1781, and for all subsequent orbits displayed here, the anti-sunward convection was very strong on the dawn side of the polar cap. Considering the propagation delay to the magnetopause from the location ISEE-3, the convection pattern responds almost immediately to the change in IMF $B Y$. At 01.22 , the $B Z$ component became northward. As the $B Z$ component became northward, the convection in the auroral oval weakened and the polar cap shrank, despite very strong anti-sunward flow in the dawn side of the polar cap.

The ground-based FPI data are shown in Fig. 12, for the period between 14 and $05: 30$ U.T. on 2 December 1981. These wind components are compared with the appropriately-sampled data from the model simulations when the IMF " $Y$ " component has either a positive or negative sense. The zonal components were measured in both the eastward (12A) and westward (12B) directions from ESRANGE, Kiruna (Note: for the ESRANGE observations (1/2 Dec, 6/7 Dec 1982) only, observations of the zonal wind component from the westward direction were made at a slightly higher geomagnetic latitude than the measurements made in the eastward direction). Moderately strong westward winds were seen of both locations ( $\max .200-300 \mathrm{~m} \mathrm{~s}^{-1}$ ) until 20: 5 U.T., when there was a steady change to very modest eastward winds $\left(50-100 \mathrm{~m} \mathrm{~s}^{-1}\right)$. After 02 U.T., the zonal wind reverted to westward for the rest of the night, but with weak values $\left(50-100 \mathrm{~m} \mathrm{~s}^{-1}\right)$. Prior to about $18 \mathrm{U} . T$., the predictions of either the $\mathrm{JB}$ or the $\mathrm{JC}$ model would have fitted the observed westward winds equally well. However, after 18 U.T., the observed low eastward wind components were very similar to the low values predicted by the JC model (i.e. the moderately disturbed simulation for IMF $B Y$ positive, as observed), while the JB model ( $B Y$ negative) would have predicted $200 \mathrm{~m} \mathrm{~s}^{-1}$ eastward zonal winds between 19 and 02 U.T.

Mcridional winds observed by the GBFPI (Fig. 13) were weak before 18 U.T.(slightly northward), and then changed (as seen to the North of Kiruna, Fig. 13A) to moderate to strong equatorward winds (200$300 \mathrm{~m} \mathrm{~s}^{-1}$ ) after 19 U.T., a relatively late time of the night (Rees et al., 1985a). To the South of Kiruna (13B), the equatorward winds were somewhat lower, $150-200 \mathrm{~m} \mathrm{~s}^{-1}$. The magnitude of the equatorward meridional winds after magnetic midnight are relatively insensitive to $B Y$, however, the period of the equatorward winds starts and ends somewhat later 


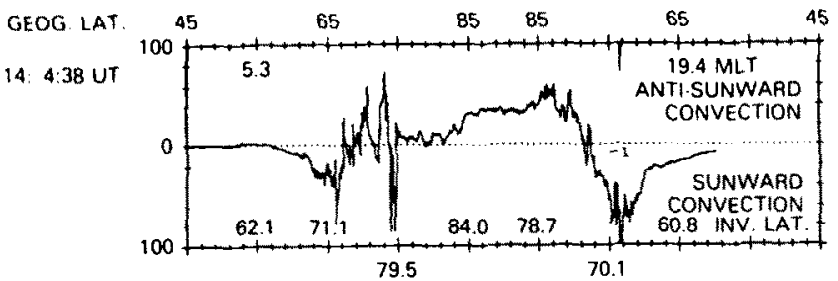

Orbit 1778

$15: 41: 19 \cup T$

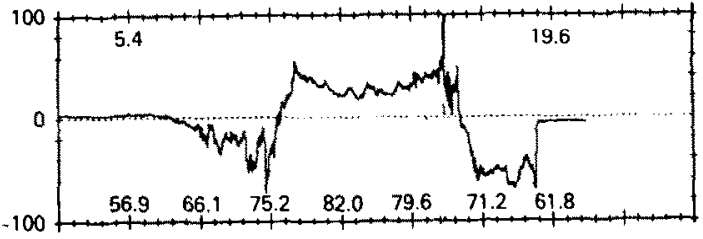

Orbit 1779

18:54:40 UT

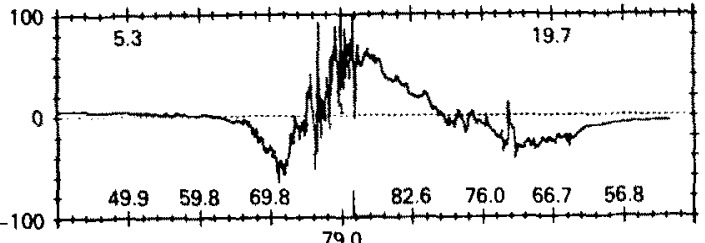

Orbit 1781

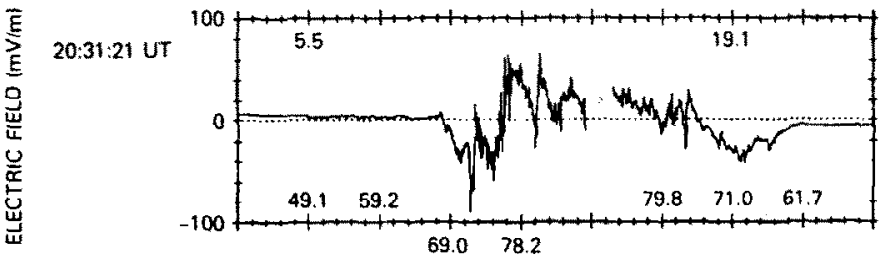

Orbit 1782

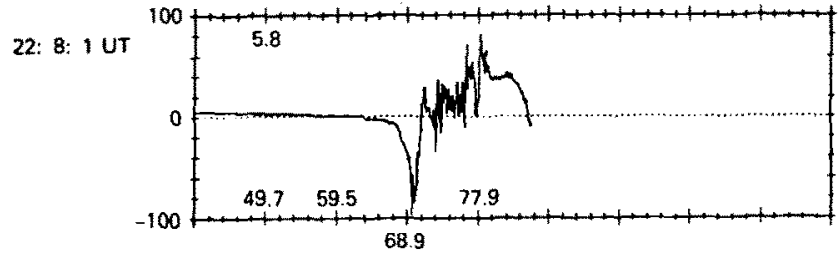

Orbit 1783

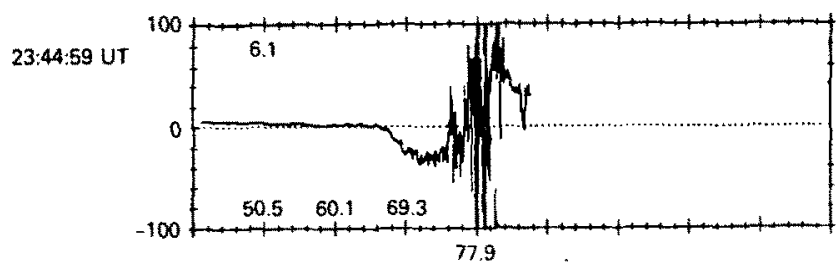

Orbit 1784

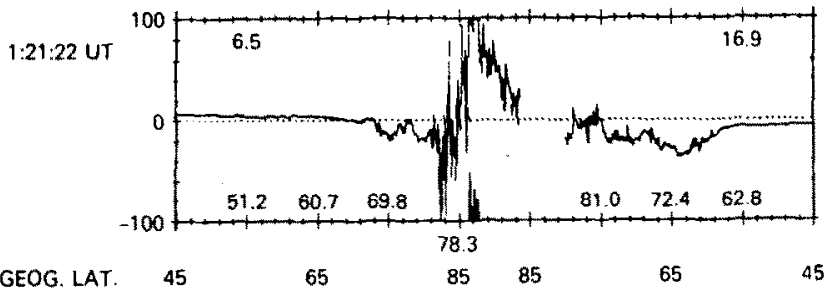

Orbit 1785

Fig. 11. ELECTRIC FIELD OBSER VATIONS BY THE VEFI ON DE-2 ON ORBITS: 1778, 1779 AND 1781 THROUGH 1785 on 1 DeC ANd 2 DeC 1981.

The meridional electric field component is shown plotted against geographic latitude. Positive $E$ field values correspond to approximately anti-sunward convection (perpendicular to the orbit plane). Whilst negative values correspond to sunward convection. In variant latitude and magnetic local time values are given in each 


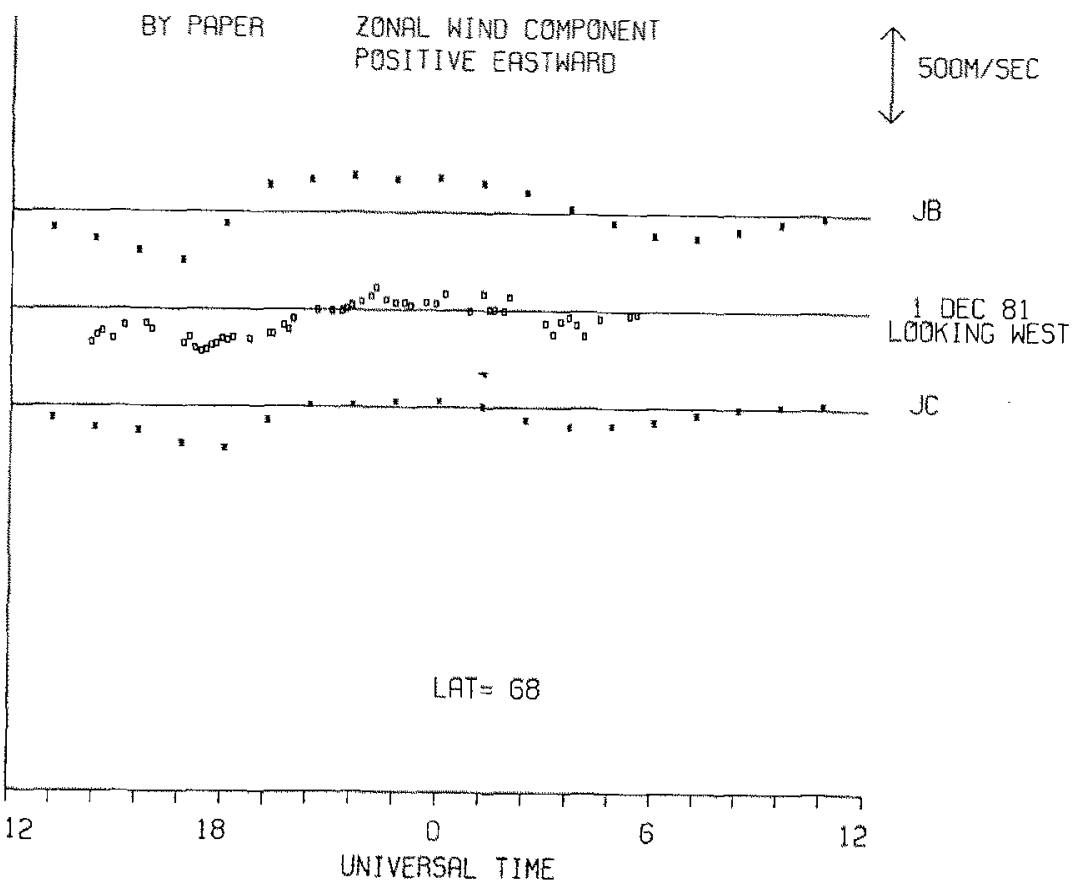

(A)

UNIVERSAL TIME

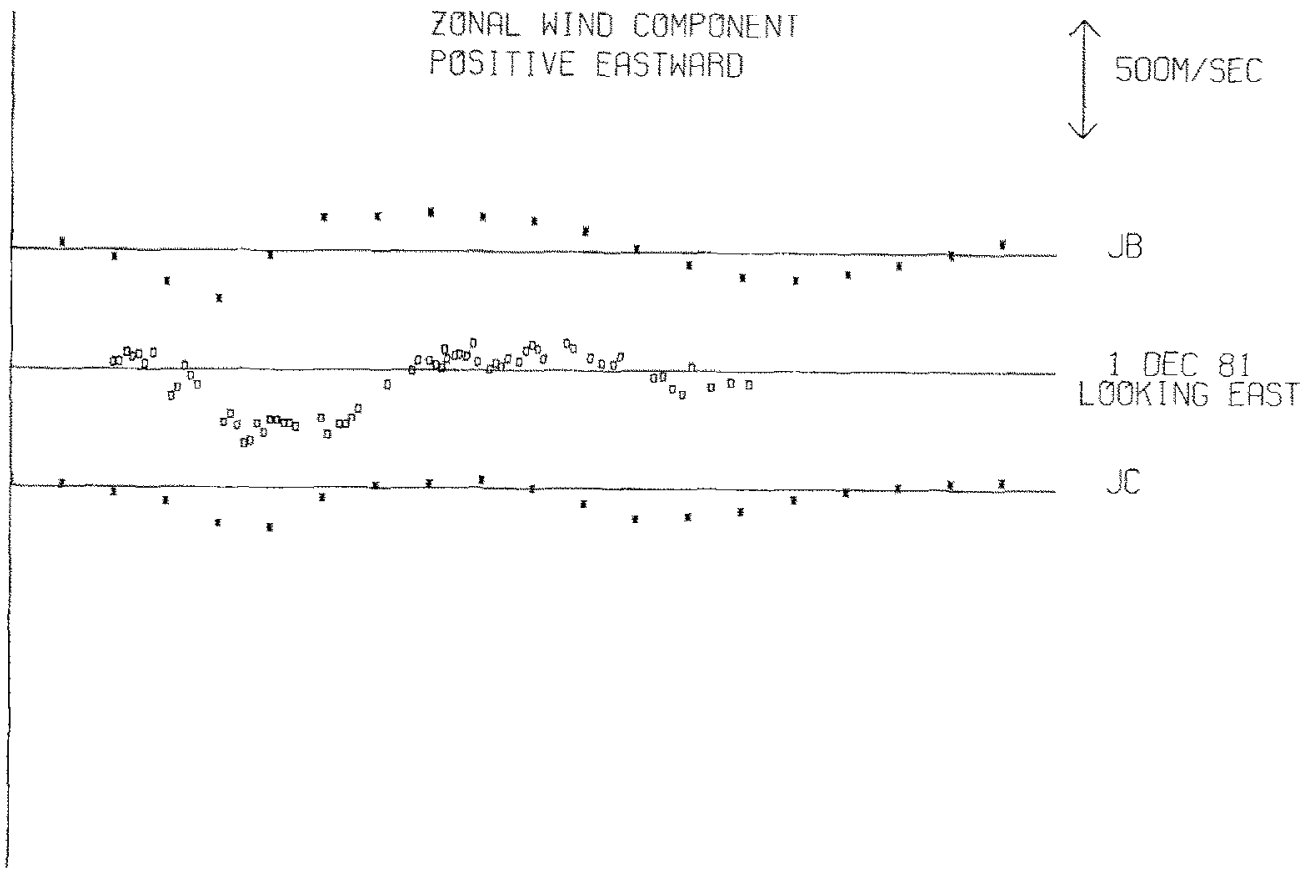

Fig. 12. ZONAL WIND COMPONENTS AS MEASURED BY THE GROUND-BASED FAaRX-PEROT INTERFEROMETER AT KIRUNA, SWEDEN,

Figure 12A shows the zonal wind component $400 \mathrm{~km}$ to the West of Kiruna, while Fig. $12 B$ shows that measured $400 \mathrm{~km}$ to the East of Kiruna. In each case the data are compared with the JC model representing $B Y$ positive, and the JB model representing BY negative. Data is shown for event $1,1 \mathrm{Dec} / 2 \mathrm{Dec} 1981$. 


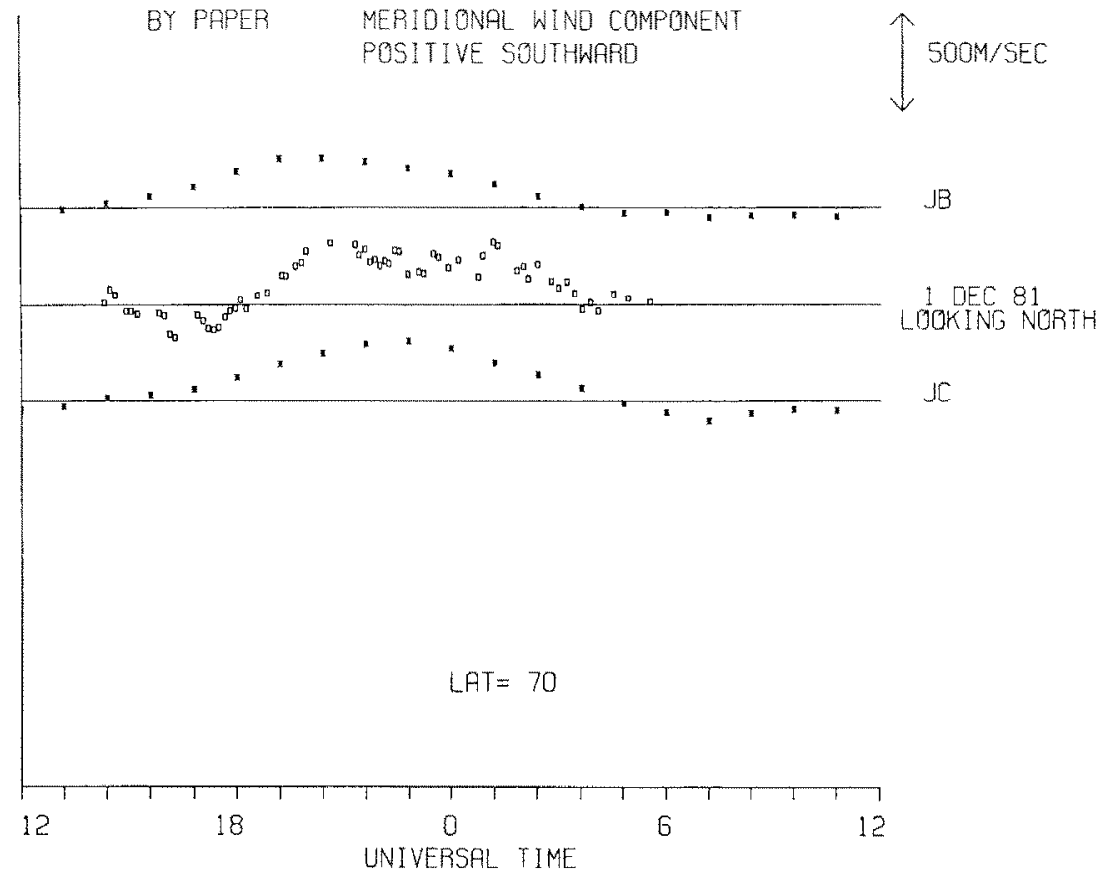

(A)

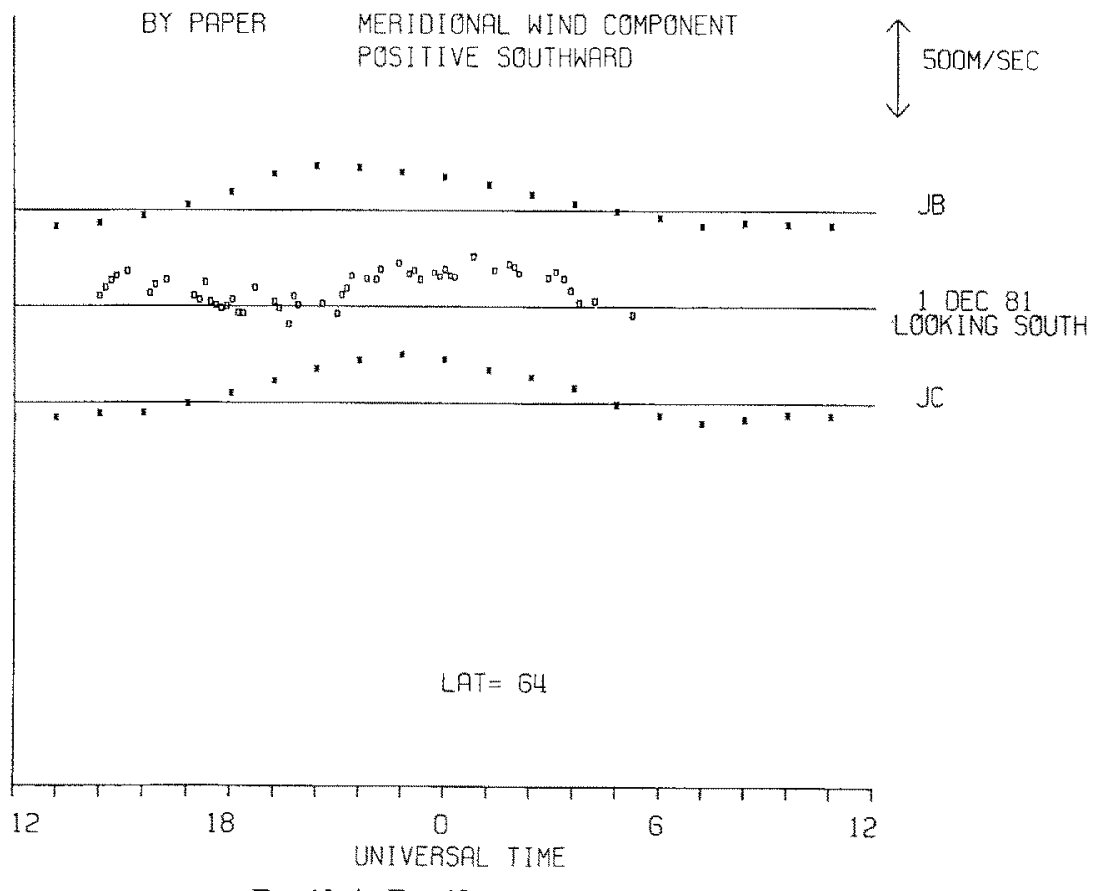

(B)

FIG. 13. As FIG. 12, EXCEPT FOR MERIDIONAL WINDS.

Figure 13A shows the meridional component $400 \mathrm{~km}$ to the North of Kiruna, while Fig. $13 \mathrm{~B}$ shows that $400 \mathrm{~km}$ to the South of Kiruna. 
when $B Y$ is positive. The magnitude of the equatorward winds observed after 20 U.T. thus agreed well with the model predictions for either sense of the $B Y$ IMF component. The time of the change from northward to southward winds was about one hour later than that predicted by either model. The actual data of $1 / 2$ December thus appear to show an exaggerated form of this tendency for a delay in the period of equatorward winds when the $B Y$ component is positive.

As seen by the $D E-2$ satellite, the polar crossing at 16 U.T. (orbit 1779) showed winds in the polar cap (Fig. 14) which were consistent with the predictions of a model comensurate with negative " $Y$ " component of the IMF which existed before 15 U.T. at the ISEE-3 spacecraft. That is, there was a maximum anti-sunward wind on the dusk side of the polar cap, combined with relatively strong eastward and equatorward winds in the dawn auroral oval. This pass is near the time when $B Y$ switch would have reached the magnetosphere, and although the convection pattern is in the process of responding (Fig. 11), the polar winds still reflect the previous state of the IMF. The JB, JC and JQ simulations from the global model have been compared with the $D E-2$ data in this figure. The JB ( $B Y$ negative) model simulation demonstrates this tendency for the highest antisunward winds to occur on the dusk side of the polar cap, and for enhanced sunward wind flow in the dawn auroral oval. The observed wind structures of orbit 1779 are, however, more extreme than the predictions of the JB model.
By the time ( $3 \mathrm{~h}$ later) of the next available $D E-2$ polar pass (orbit 1781, Fig. 15) there was a remarkable change in the wind and electric field structure. Figure 11 shows that the peak ion drifts are now on the dawn side of the polar cap, and a very strong anti-sunward wind jet has developed, with a peak velocity of $1300 \mathrm{~m} \mathrm{~s}^{-1}$ on the dawn side of the polar cap. This is, in fact, one of the highest thermospheric wind speeds observed by $D E-2$, and it considerably exceeds the wind speed predicted by the relevant model (JQ) simulation for the IMF $B Y$ positive condition. The maximum wind velocity and the maximum anti-sunward ion speed are very close to the same values.

The agrcement in the shape of the simulated and observed wind structures over the polar cap is the most important factor. The cross-polar cap potential used in the theoretical simulations (Table 3) was significantly lower than the value implied by the data from VEFI at this time.

The next orbit (1782, Fig. 16), at 20:45 U.T., again shows the characteristic wind patterns and electric field patterns of the prevailing positive $B Y$ component of the IMF. The peak wind velocities are somwhat less than those observed on orbit 1781, but the structure agrees very well with the wind pattern simulated by the JQ model. The VEFI data (Fig. 11) show that at this time, the cross-polar cap potential was close to the value used in the model simulations (about $80 \mathrm{kV}$ ). Thus, within 2$3 \mathrm{~h}$ of the arrival of the $B Y$ switch of the magnetosphere, both the Kiruna and $D E-2$ data sets indicate that the wind had responded to the convection pattern switch.

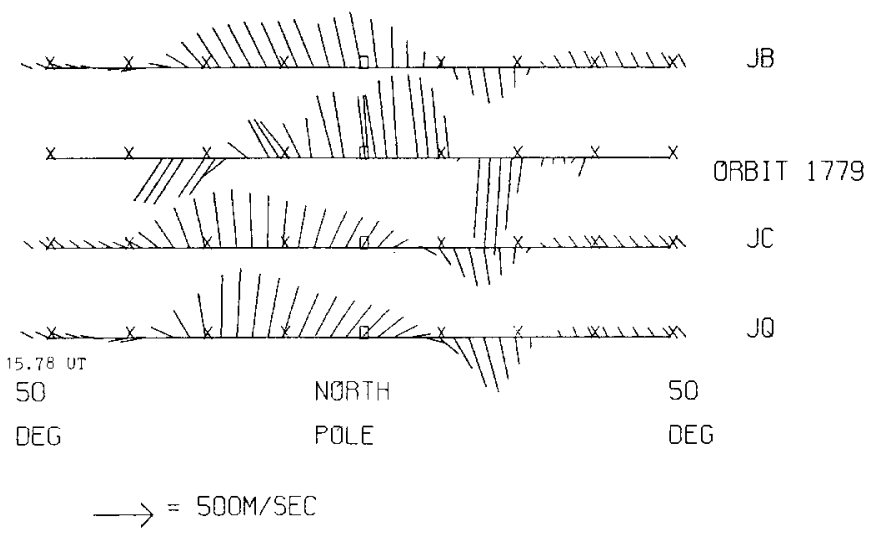

$* S \operatorname{NN} *$

FIG. 14. CUMPAKISON OF THE VECTOR WINDS DERIVED FROM THE WATS AND FPI INSTRUMENTS OF DE-2 DURING THE POLAR PASS 1779 ON 1 DEC 1981 WITH THE APPROPRIATE SAMPLES FROM THE JC AND JQ MODELS(BY POSITIVE) AND THE JB MODEL ( $B Y$ NEGATIVE). 


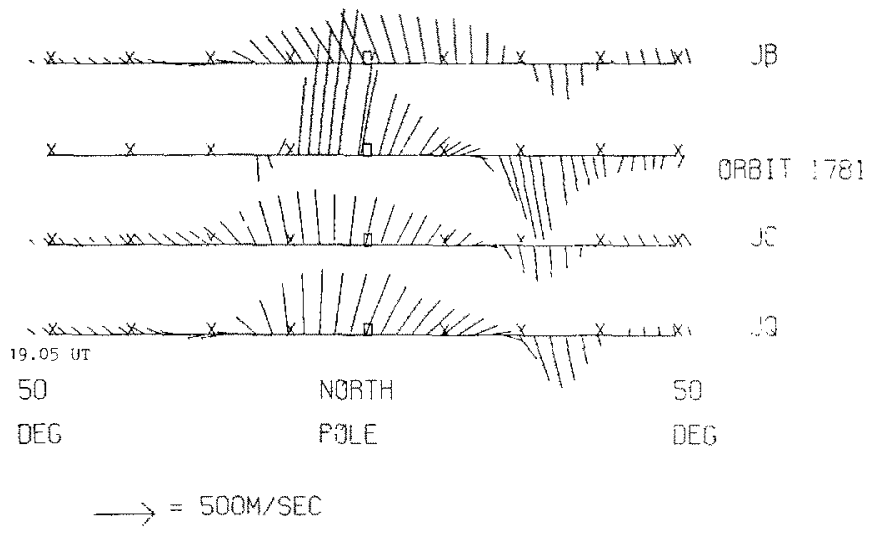

$\times \operatorname{Sun} x$

Fig. 15. SAME AS FIG. 14, BUT FOR ORBIT 1781 (19.05 U.T., 1 DEC 1981).

\section{PERIOD 2. 6 DECEMBER 1981}

\section{BY positive throughout period}

Figure 17 shows the IMF from ISEE-3 during this period. The total field strength was modest, $5 \mathrm{nT}$, there was a small and fairly consistent southward component, and the $B Y$ component was systematically positive.

The GBFPl winds (Fig. 18 zonal winds, Fig. 19 meridional winds) showed similar trends to the data of 1 December (PERIOD 1). To the west of Kiruna (Fig. $18 \mathrm{~B})$ there were modest westward winds before about 20-21 U.T., and with equatorward winds of around $200 \mathrm{~m} \mathrm{~s}^{-1}$ setting in after 20 U.T. After 21 U.T. there were weak eastward zonal winds barely reach- ing $100 \mathrm{~m} \mathrm{~s}^{-1}$ at any time. To the East of Kiruna (Fig. $18 \mathrm{~A})$, at lower geomagnetic latitude, the data indicate that there was no effective penetration by the sunward ion convection region of the dusk auroral oval. The zonal winds to the east of Kiruna were thus indistinguishable from a mid-latitude wind circulation, with weak eastward winds until 23 U.T. and weak westward winds for the remainder of the night. The break in wind data measured to the South of Kiruna was due to the interference from the moon which was close to full phase and was also close to the "South" viewing direction at this time. The GBFPI winds were similar to the simulated winds (Model JC) for the prevailing $B Y$ positive situation.

The data from the sequence of $D E-2$ orbits (Fig. 20)

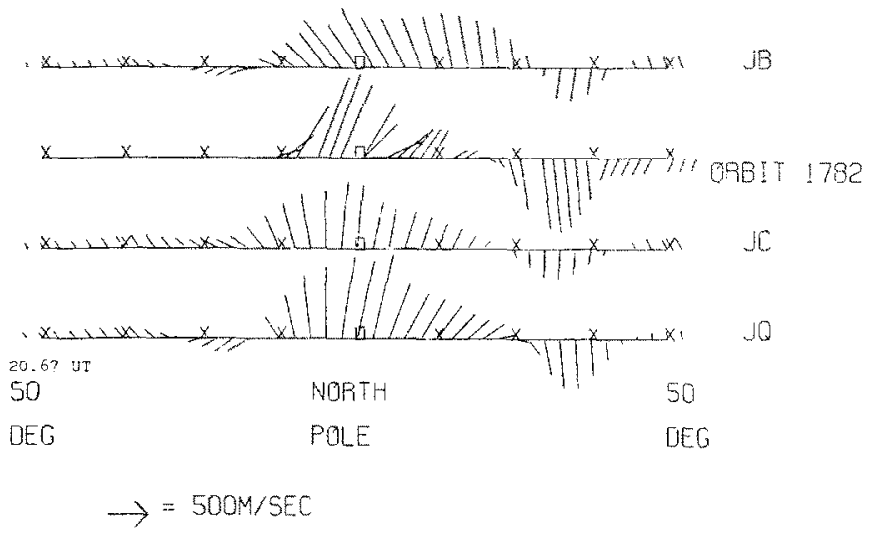


ISEE-3 INTERPLANETARY MAGNETIC FIELD 1981 DAY 340 I,S COORDS 5 M AVG DAY 341

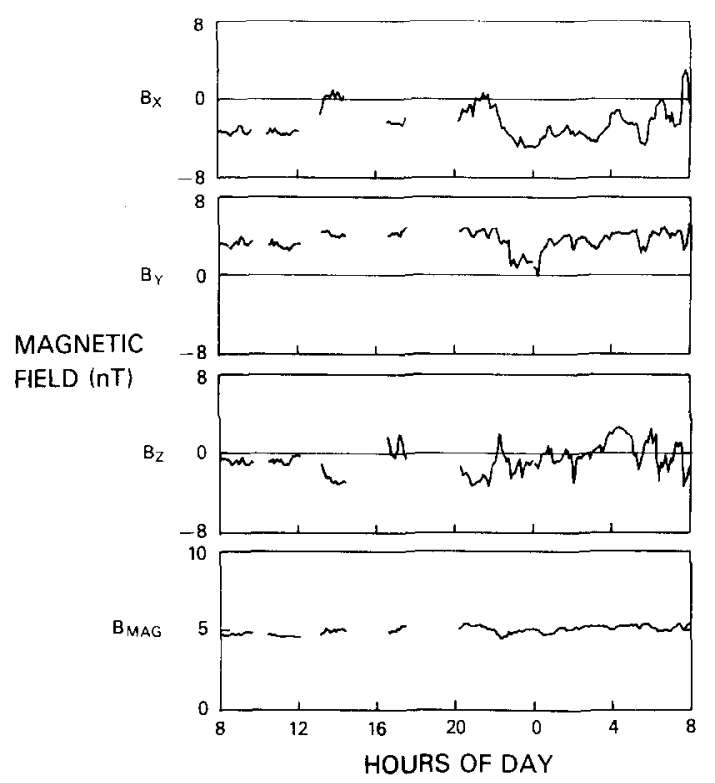

FIG. 17. SAME AS FIG. 10, BUT ISEE-3 IMF DATA FOR PERIOD 2, 6 DEC/7 DEC 1981.

shows that the high latitude electric field structures as measured by VEFI were entirely consistent with the IMF $B Y$ positive situation, from the first orbit in the sequence (1849 at $08: 40$ U.T.) through 23:00 U.T.

The satellite wind data described a sequence of observations from an orbit which crosses near the cusp region (orbit 1849, Fig. 21) to one which crosses the night side of the geomagnetic polar cap (orbit 1856, Fig. 24). The comparisons between the data and the simulations show that there were persistent strong antisunward wind on the dawn side of the polar cap. Also, in the region of the dawn auroral oval, the winds were either weakly sunward (orbit 1856) or directed antisunward (1849, Fig. 21 and 1853, Fig. 22). No data were available for the dawn oval crossing of orbit 1854 (Fig. 23).

\section{PERIOD 3. 25 DECEMBER 1981}

\section{BY negative until 05 U.T. (26 December)}

The IMF data (Fig. 25) show that the $Y$ component of the IMF was systematically negative until 05 U.T. on the morning of 26 December. The $Z$ component was directed southward prior to 16 U.T. and variable for the remainder of the period, while the total IMF was relatively weak, never more than about $6 \mathrm{nT}$. Despite the relatively weak total IMF, the southward component ensured that coupling of energy and momentum from the solar wind to the magnetosphere was large enough to generate a significant geomagnetic disturbance and to drive relatively large thermospheric winds within the auroral oval. Between 02 and 06 U.T. the total IMF fell to between 2 and $3 \mathrm{nT}$, an extremely low value.

A sequence of observations of the polar cap electric field from VEFI of $D E-2$ are shown in Fig. 26 for this period. The first orbit in the sequence, at 15:40 U.T. shows a symmetric convection in the polar cap. After about 16 U.T., the polar electric field patterns are all consistent with the negative value of $B Y$. There is strong anti-sunward convection on the dusk side of the polar cap in the Northern Hemisphere, and stronger antisunward convection on the dawn side of the polar cap in the Southern Hemisphere. The asymmetric pattern, with the stronger dusk side polar cap convection has also been deduced by Heppner (1977) to be a $B Y$ negative (Northern Hemisphere) effect. It may also be related to the very small value of $B Z$ during the preceding $2 \mathrm{~h}$. For all these passes the electric field values are, for the most part, small and the polar cap is contracted poleward. This is especially true in the last pass when, as noted above, the IMF drops to near $3 \mathrm{nT}$ and $B Z$ was positive.

The thermospheric winds (measured by the groundbased FPI-Fig. 27 zonal winds, Fig. 28, meridional winds) switched to the equatorward sense as early as 15 U.T. There were quite strong westward winds (300 $\mathrm{m} \mathrm{s}^{-1}$ ) prior to 21 U.T., and relatively strong $\left(>200 \mathrm{~m} \mathrm{~s}^{-1}\right.$ ) eastward winds between 21 and 03:30 U.T. Later in the night, all wind components moderated to about $100 \mathrm{~m} \mathrm{~s}^{-1}$, reflecting the very low IMF magnetic field after 02 U.T. The early switch to equatorward winds and the strong eastward winds after 21 U.T. are characteristic of the simulated thermospheric winds for conditions when the IMF has a negative $B Y$ component (Models JB). The magnitude of the westward and equatorward winds were larger than might have been anticipated considering the relatively small value of the total IMF during the period before 02 U.T.

The relatively late switch from westward to eastward winds (21 U.T.) appears to be the signature of the small total IMF, leading to a poleward contraction of the auroral oval. The southward component of the IMF seems to have been the effective factor in enhancing the transfer of momentum and energy from the solar wind to the magnetosphere during this period, despite the low total IMF.

\section{PERIOD 4. 12/13 FEBRUARY 1982}

IMF BY negative, BZ southward, strong IMF (>20 nT) This set of observations was taken during an 
Theoretical and empirical study of the response of the high latitude thermosphere

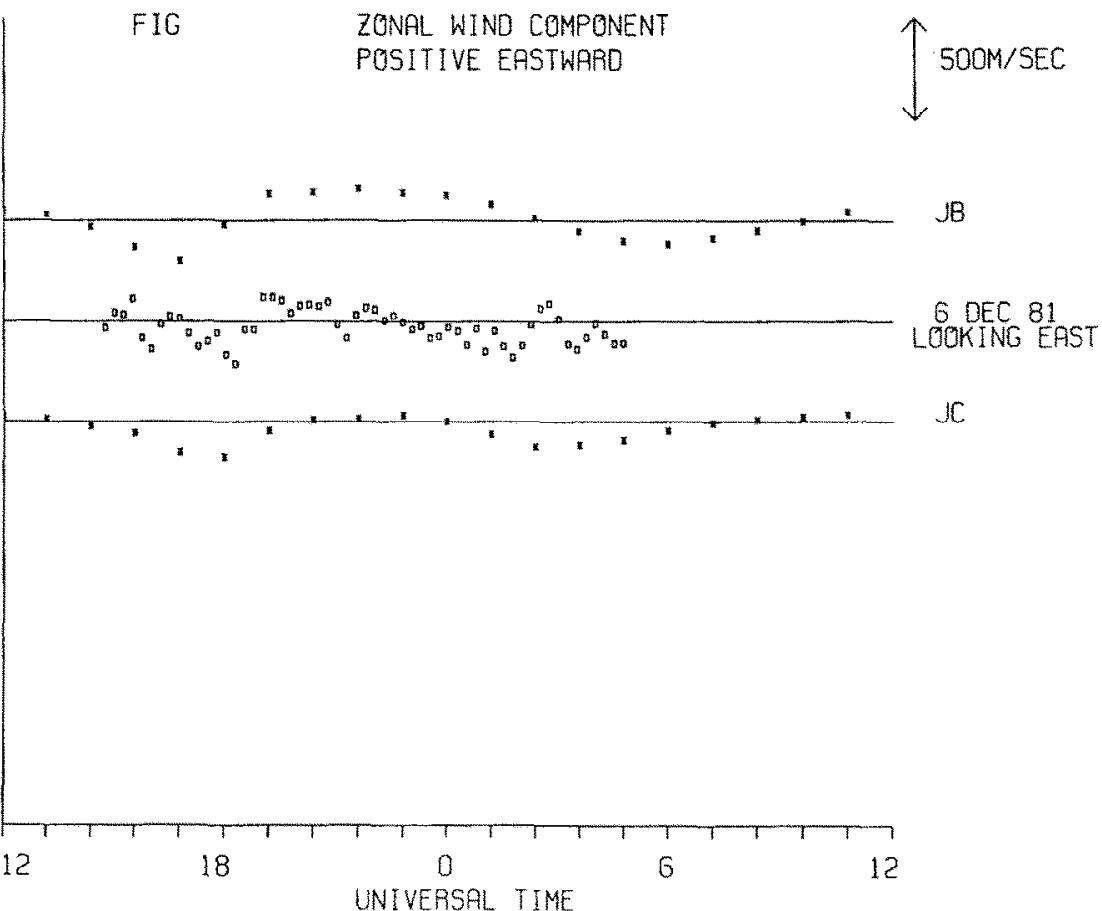

(A)

UNIVERSAL TIME

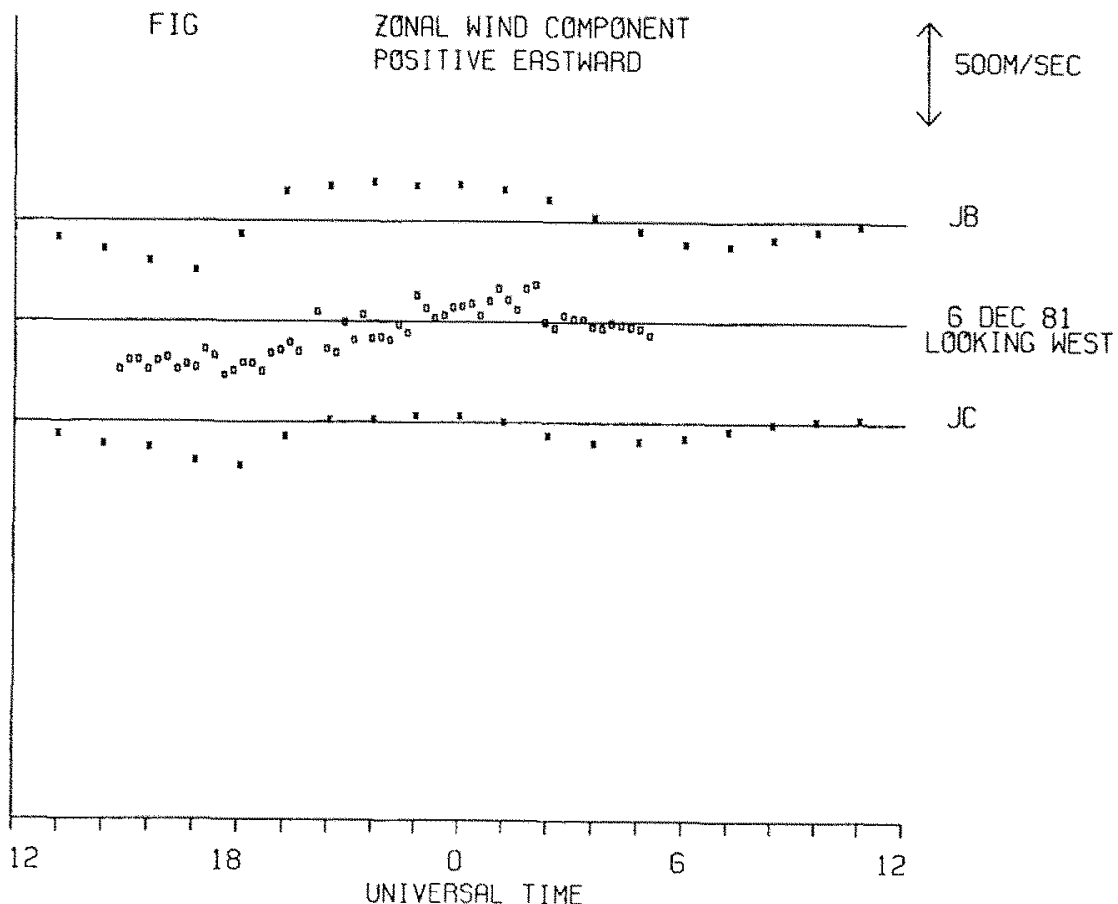

Fig. 18. Same as Fig. 12, But GBFPI zonal Wind data for 6 DeC/7 DeC 1981 from KiRuna. 


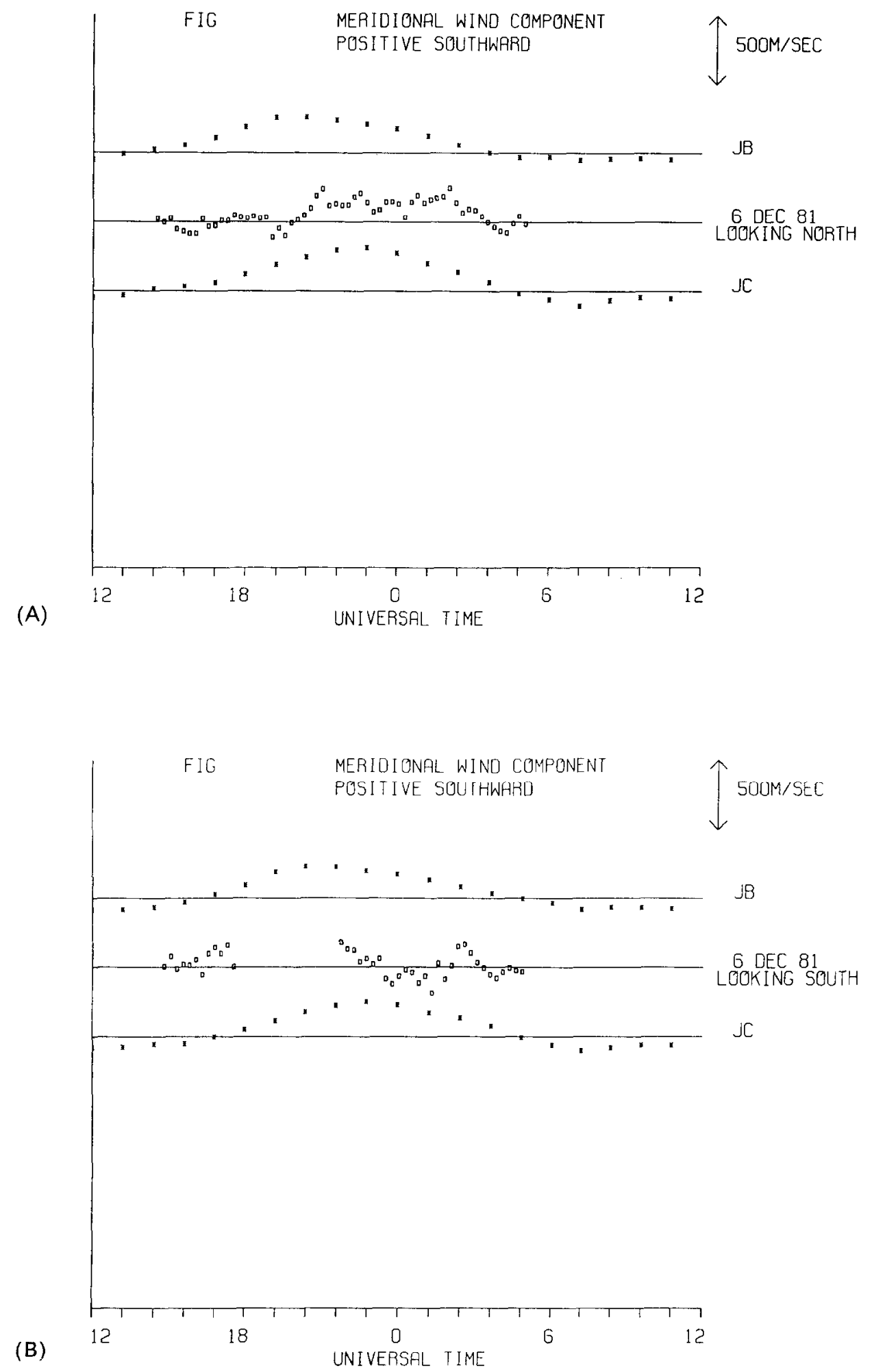

Fig. 19. Same as Fig. 13, But GBFPI Meridional wind data For 6 DeC/7 DeC 1981 from Kiruna. 


\section{DEC. 1981}

\section{$\mathrm{DE}-2$}

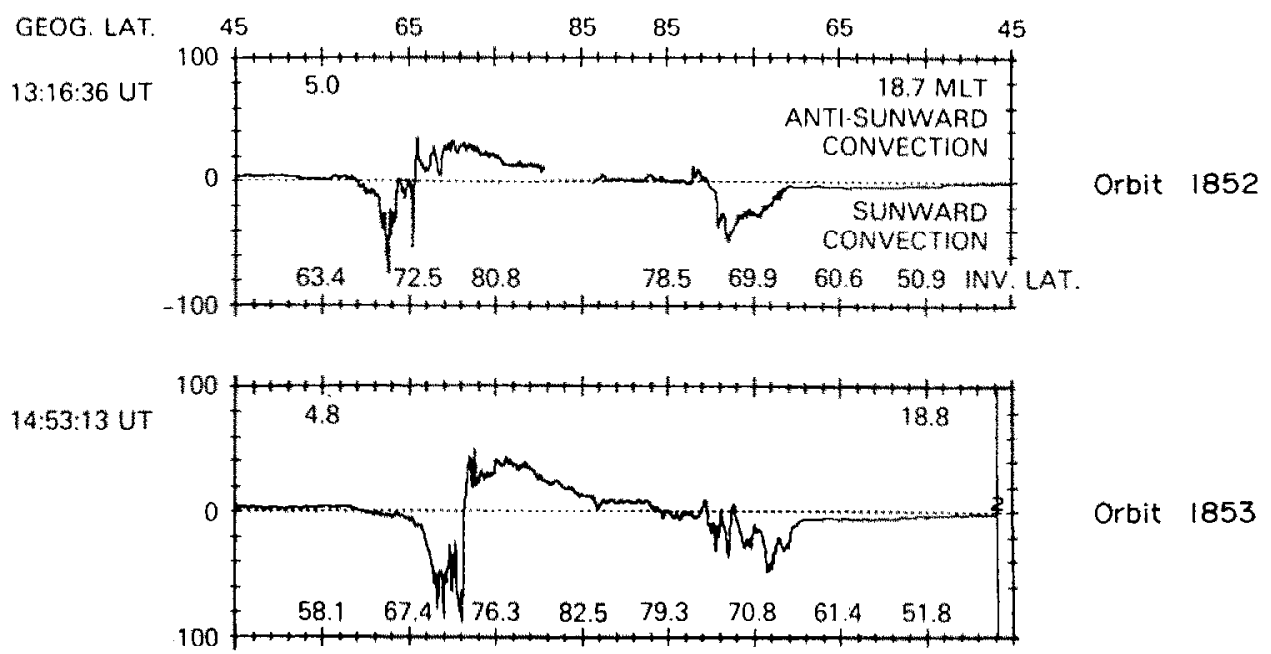

$\frac{E}{E}$

$16: 29: 56$ UT

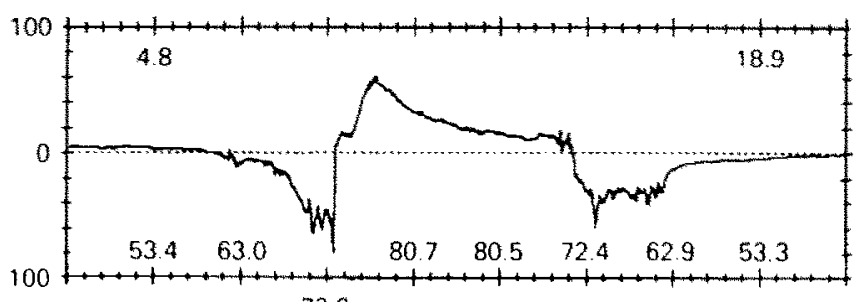

Orbit 1854

Orbit 1856
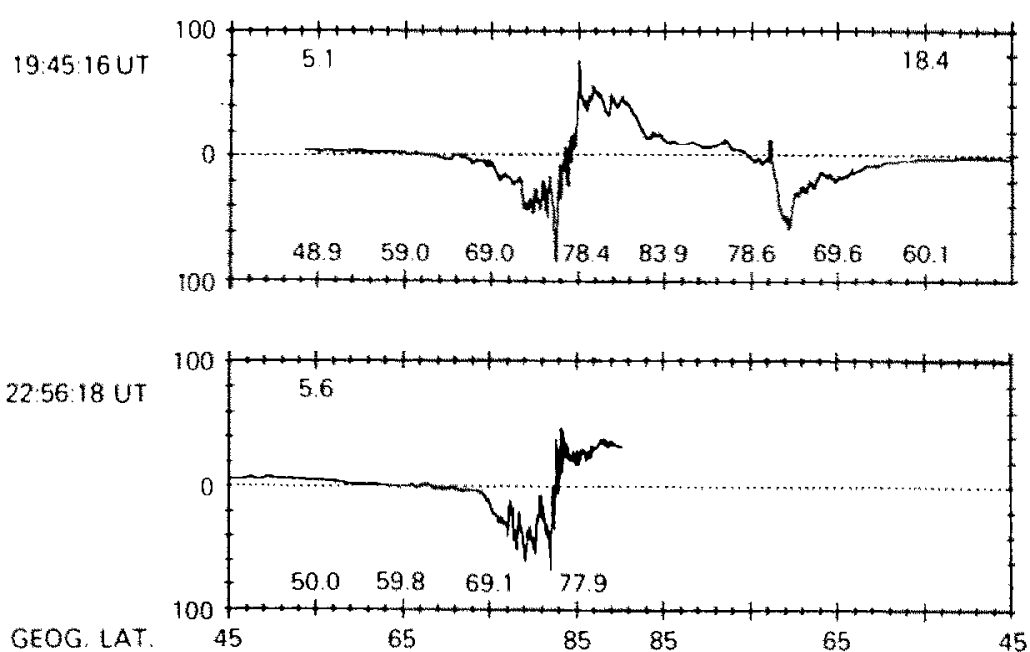

Orbit 1858

Fig. 20. SAME AS FIG. 11, BUT FOR VEFI dATA FROM ORBIT: 1853,1854 AND 1856 OF 6 DEC/7 DEC 1981. 


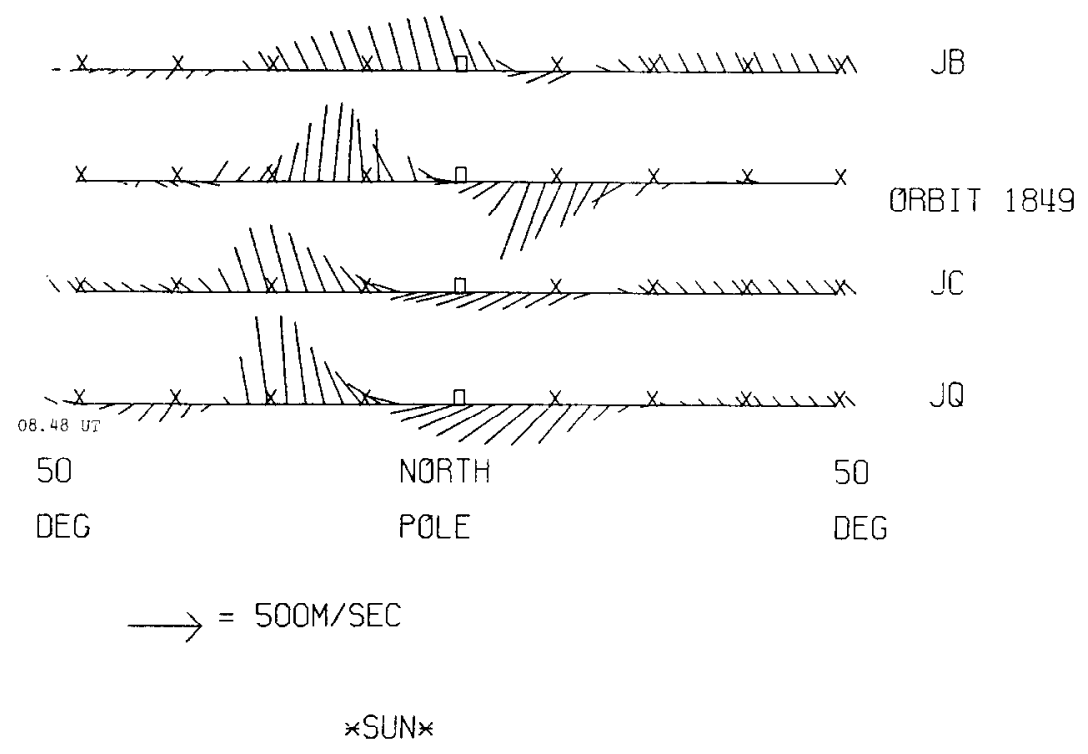

Fig. 21. SAME AS Fig. 14, BUt SATELlite WindS From ORBit 1849.

extended disturbed period between 10 and 15 February 1982. The IMF data from ISEE 3 (Fig. 29), show the extremely large values of the IMF magnetic field, and the strong negative values of $B Y$. The thermospheric winds observed at Kiruna are shown in Figs. 30 (zonal winds) and 31 (meridional winds) respectively. The winds which were observed in the period post-magnetic midnight and in the early morning hours of $12 / 13$ February 1982 are the strongest eastward and equatorward winds recorded in 400 nights of observations with good observing conditions from Kiruna since 1980 (Rees et al., 1983c).

The $Z$ component of the IMF was continuously negative, i.e. the IMF was strongly southward, after

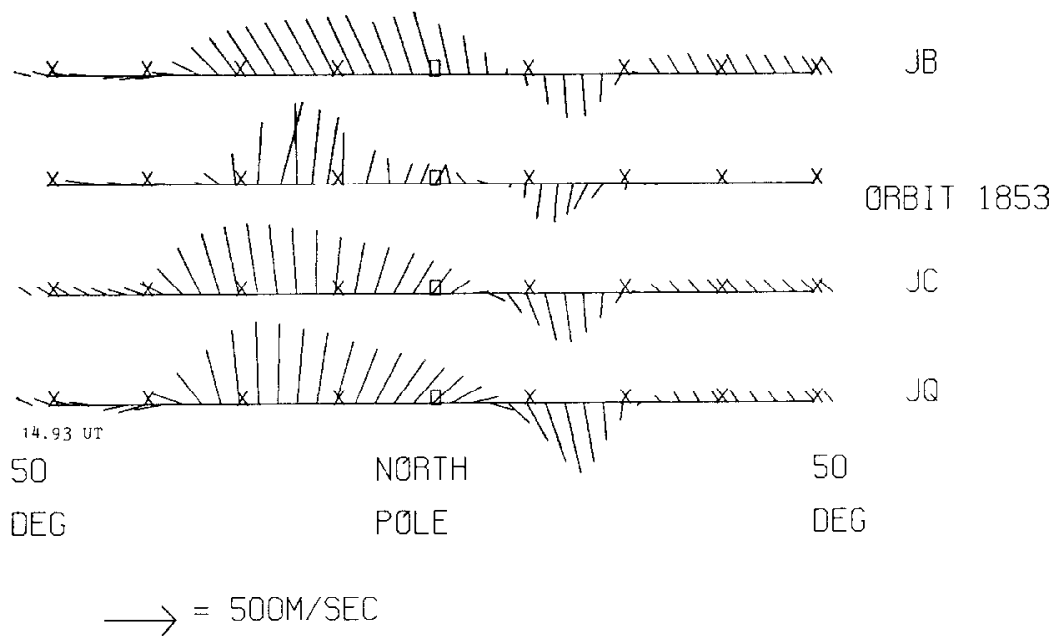

Fig. 22. SAME AS Fig. 14, BUT SATELLITE WINDS FROM ORBIT 1853. 


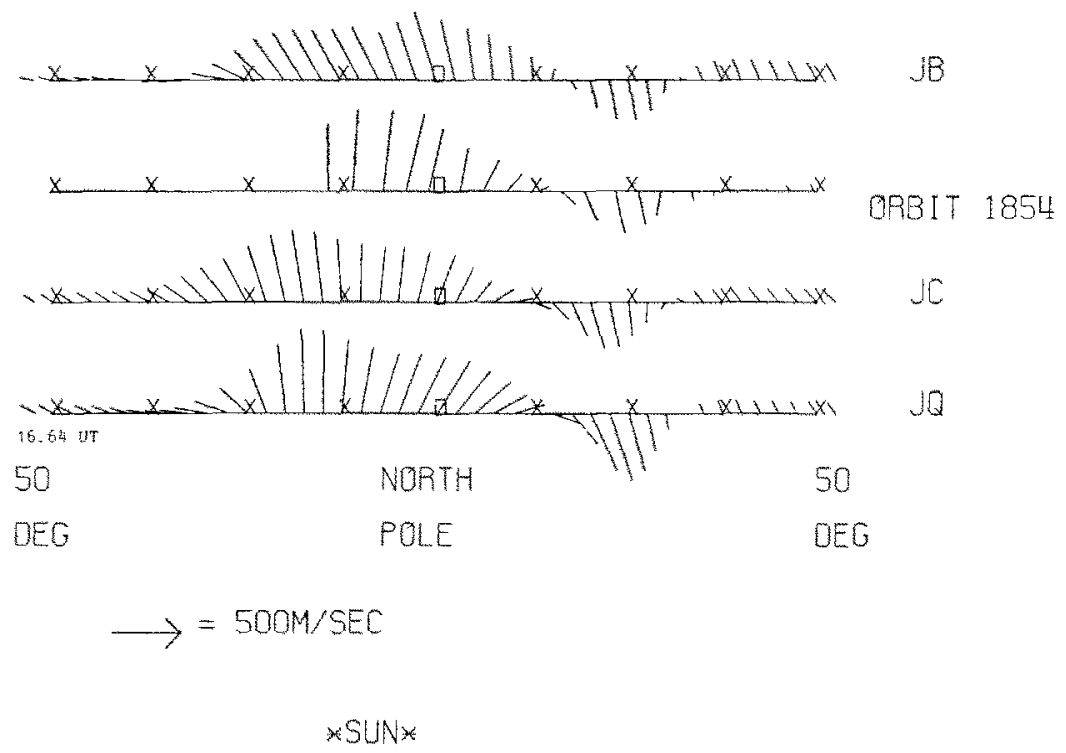

Fig, 23. SAME as Fig. 14, BUt SATELLITE WiNdS From ORBIT 1854.

$16 \mathrm{U} . \mathrm{T}$. on the 12 th, and the $B Y$ component was also negative for an extended period ( $40 \mathrm{~h}$ from 02 U.T. on 12 February). Under these conditions, there would have bcen a major equatorward expansion of the auroral oval (Rees et al., 1985a; Siscoe, 1983, and references therein). The very early transition of the GBFPI winds at Kiruna to equatorward and eastward directions (both at 19 U.T.) is evidence that this was the case. No $D E-2$ polar passes were available for this period, however, magnetospheric particle precipitation data available from the NOAA 6 and 7 satellites (Evans, 1984, private communication), confirmed that the auroral precipitation boundaries were expanded far equatorward of their normal locations throughout this

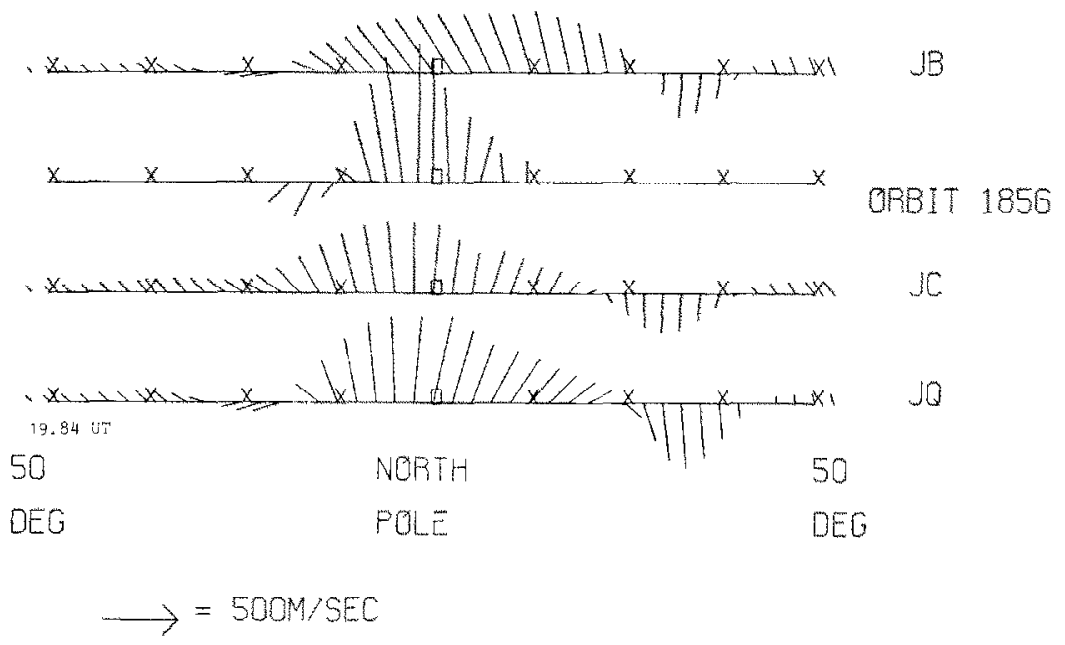

Fig. 24. Same as Fio. 14, bUt SATELUITE winds from orbit 1856. 
ISEE-3 INTERPLANETARY MAGNETIC FIELD 1981 DAY 359 I,S COORDS $5 \mathrm{M}$ AVG DAY 360

MAGNETIC
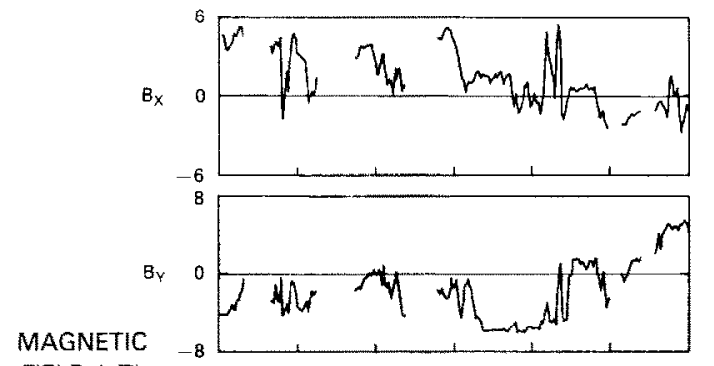

FIELD inT)

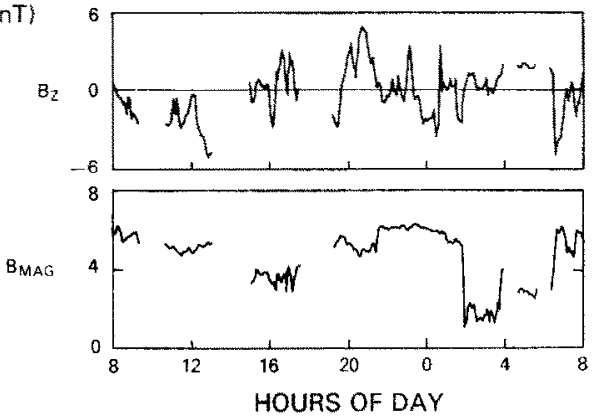

Fig. 25. SAME AS Fig. 10, IMF DATA FROM ISEE-3 FOR 25 Dec/26 Dec 1981 (Perion 3).

period, and that intense precipitation fluxes were measured within the auroral oval crossings of the two spacecraft.

The extreme eastward and equatorward thermospheric winds throughout the midnight and morning auroral oval during the period between 20 and 03 U.T. are structured, and the peak velocities follow particularly large geomagnetic disturbances during the period about U.T. midnight. The combination of the early transition to eastward and equatorward winds, and the very high wind velocities, are characteristic of the extremely disturbed geomagnetic conditions. The very strong eastward winds after magnetic midnight are characteristic of the simulation with the negative sense of the " $Y$ " component of the IMF. We have not, as yet, attempted a "storm" simulation with $B Y$ negative, reflecting the expanded sizc of the auroral oval, and a cross-polar cap electric potential of perhaps $150 \mathrm{kV}$ or larger, due to the lack of available empirical data on the polar electric field at any time during this period.

It is possible, however, to extrapolate from the simulations discussed by Rees et al. (1985a). Their simulations were carried out to examine the behaviour of the westward thermospheric jetstream of the evening auroral oval during extremely disturbed periods. In their simulations, the auroral oval winds were greatly increased during situations such as 17 December 1982, where the IMF was rather less disturbed than that observed during the 12 February 1982 event. Strong cross-polar cap anti-sunward winds are also generated during these major disturbances. These may be observed at auroral oval locations such as Kiruna as strong equatorward winds after magnetic midnight and in the early morning hours. Symmetric polar electric field distributions as used in the simulations discussed by Rees et al. (1985a) produced eastward winds in the dawn auroral oval, but with a maximum wind of only $300 \mathrm{~m} \mathrm{~s}^{-1}$, compared with the $700 \mathrm{~m} \mathrm{~s}^{-1}$ observed close to midnight U.T. $12 / 13 \mathrm{Feb} 1982$.

A negative " $Y$ " component of the IMF has a propensity for enhancing the eastward thermospheric jetstream in the morning auroral oval in the Northern Hemisphere, as displayed in the simulations and in the data discussed already. However, it appears that the extreme winds of the $12 / 13$ February event were caused by a combination of the following five factors:

I. Strong total IMF ( $>20 \mathrm{nT})$,

II. Negative IMF $Z$ component (southward),

III. Negative IMF $Y$ component,

IV. Expanded auroral oval and enhanced cross-cap potential,

V. Enhanced magnetospheric particle precipitation.

\section{SUMMARY}

Theremospheric wind data from the Dynamics Explorer-2 satellite and from a ground-based FabryPerot interferometer located at Kiruna, Northern Sweden, obtained during periods of consistent positive or negative values of the " $Y$ " component of the IMF have been compared with simulations by a global threedimensional thermospheric model. This model has used, as part of the description of the geomagnetic input, a polar convection electric field with a dependence on the sense of the " $Y$ " component of the Interplanetary Magnetic Field.

The polar electric field data available for four of the periods examined here confirmed that the characteristic structures of polar ion flow associated with the positive or negative " $Y$ " component of the IMF did actually occur. In the Northern Hemisphere strong anti-sunward ion flows occurred on the dawn side of the geomagnetic polar cap when $B Y$ was positive, and on the dusk side when $B Y$ was negative.

The comparison of observed and modelled thermospheric winds has demonstrated that the high latitutude circulation does have a distinctive response to the sense of the $B Y$ component of the Interplanetary Magnetic Field. In particular, strong anti-sunward wind jets on the dawn side of the polar cap can be 
25 AND 26 DEC. 1981

DE-2
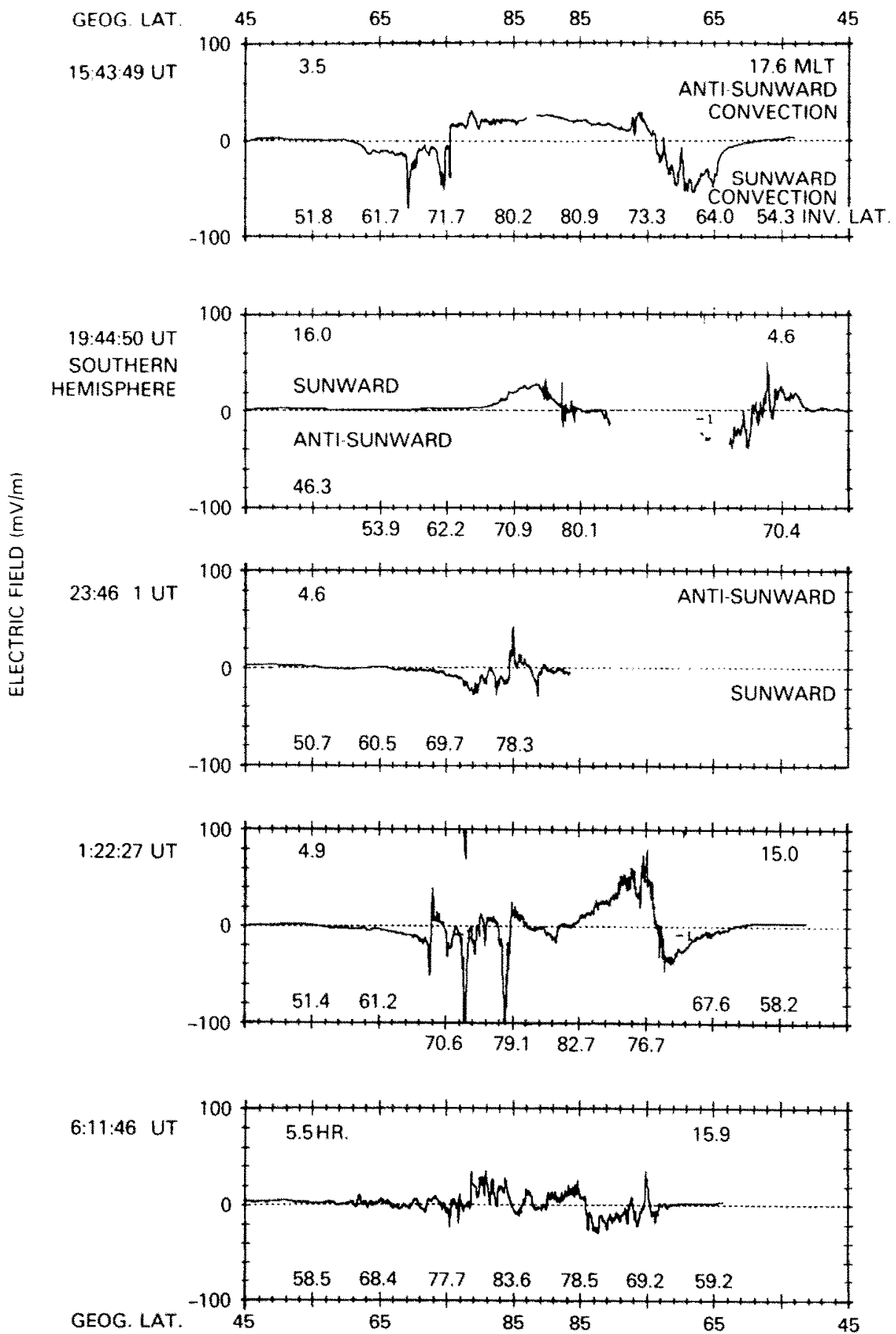

Fig. 26. SAME AS Fig. 11, BUT For VEFI DATA FROM ORBITS: 25/26 DEC 1981.

Note that the Southern Hemisphere passes have been plotted from dusk to dawn to emphasize the enhanced convection on the dawnside of the polar cap corresponding to the enhanced convection on the dusk side in the Northern Hemisphere for $B Y$ negative. 


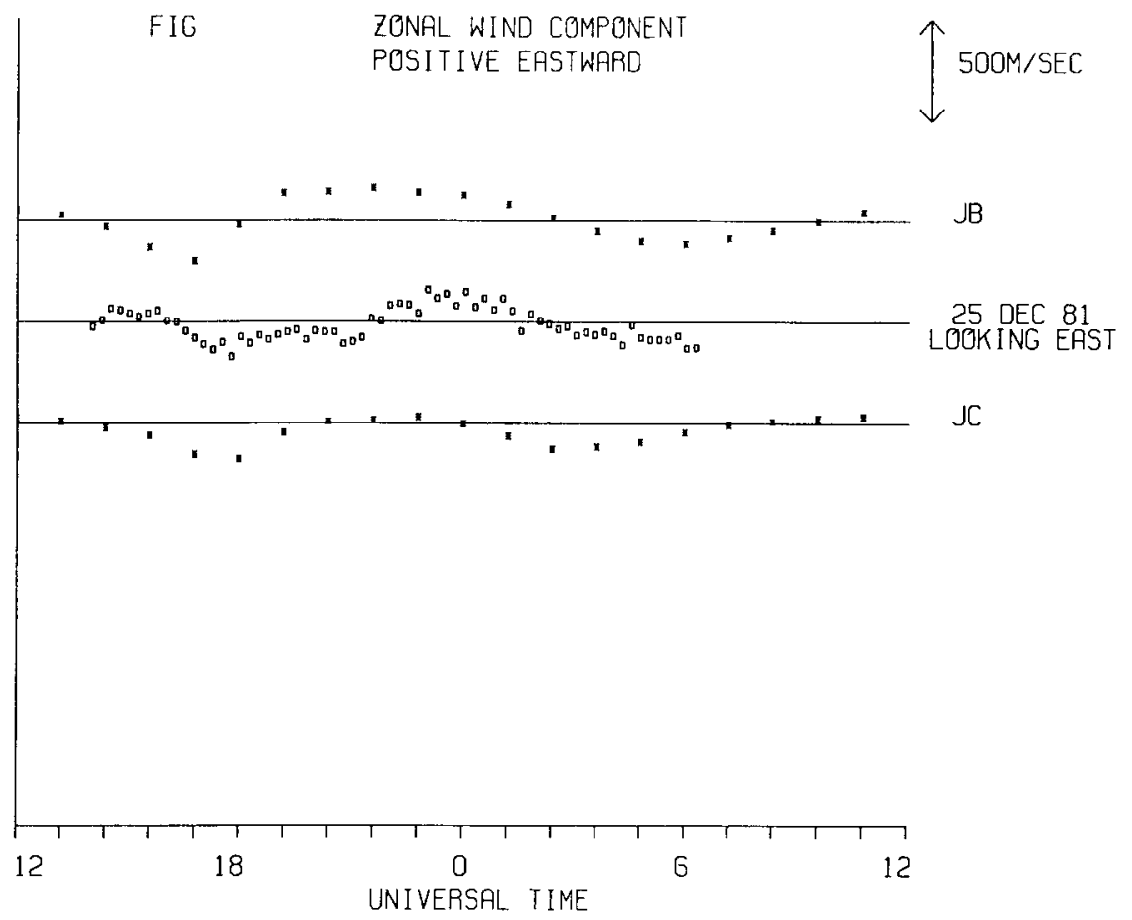

(A)

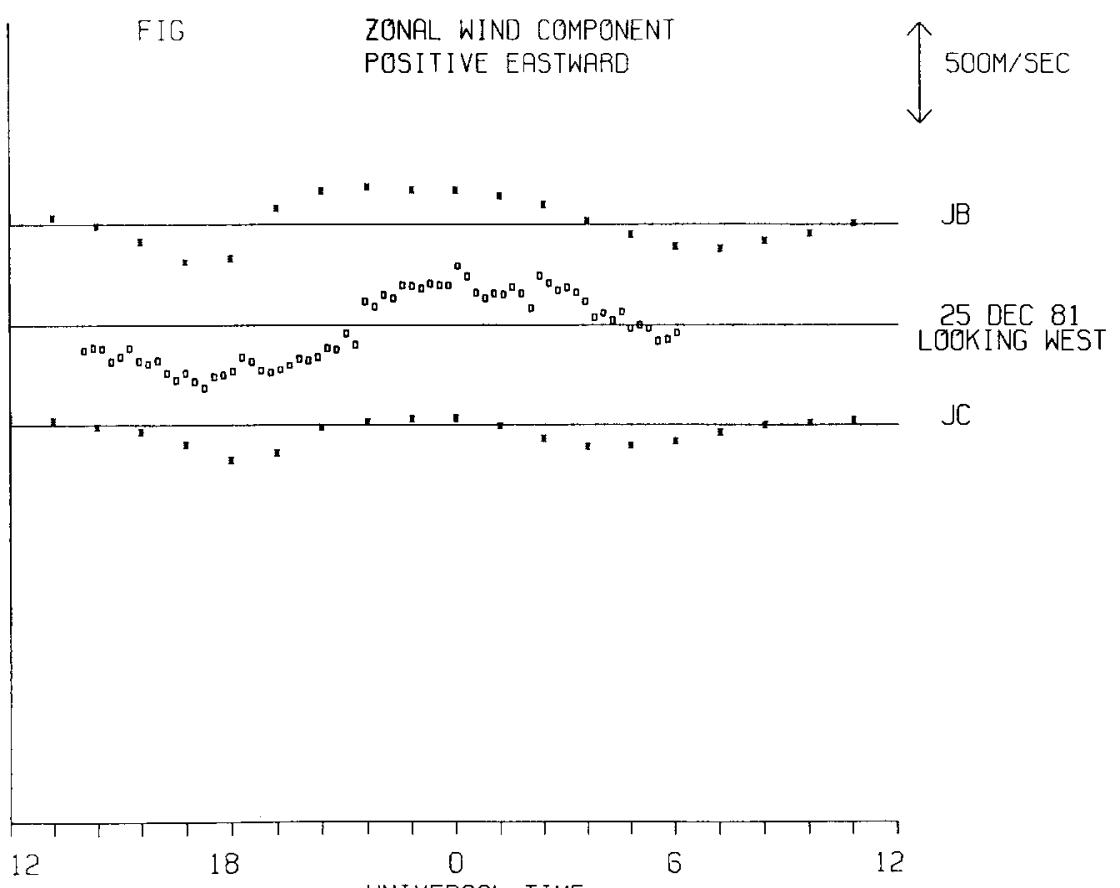

(B)

UNIVERSAL TIME

Fig. 27. SAME as Fig. 12, ZONAL WINDS From THE KIRUNA GBFPI FOR 25/26 DEC 1981. 
Theoretical and empirical study of the response of the high latitude thermosphere

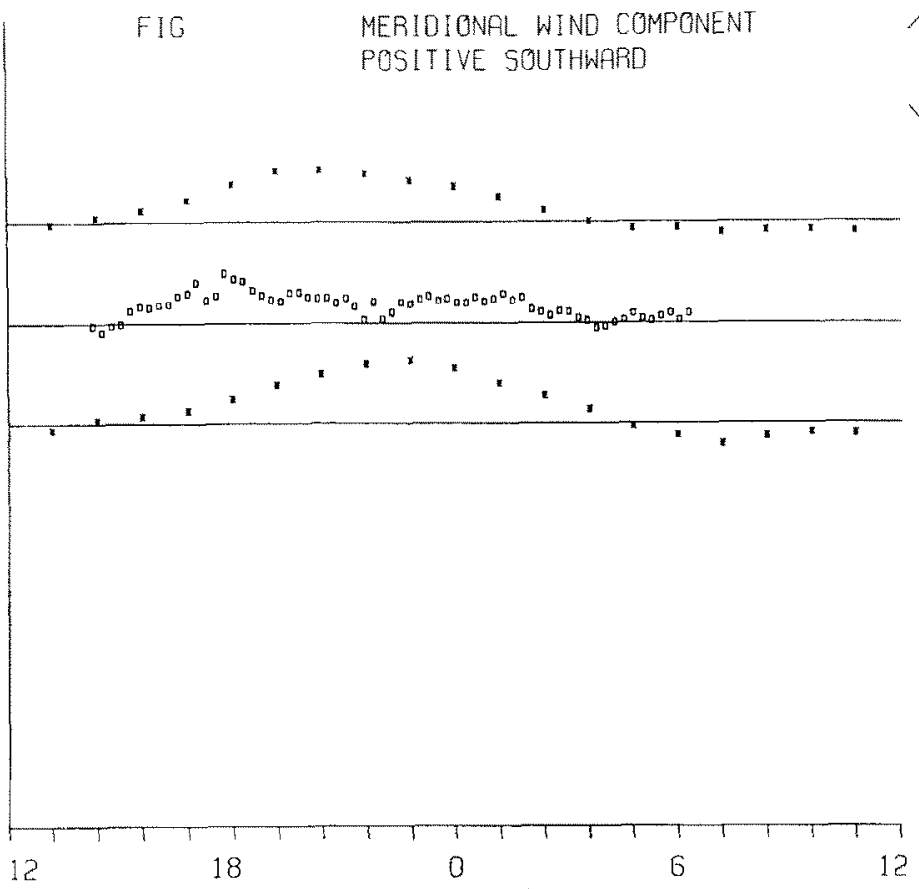

(A)

UNIVERSAL TIME

$\uparrow$ SOOM/SEC

$J B$

25 DEC 81

LOOKING NORTH

$J C$

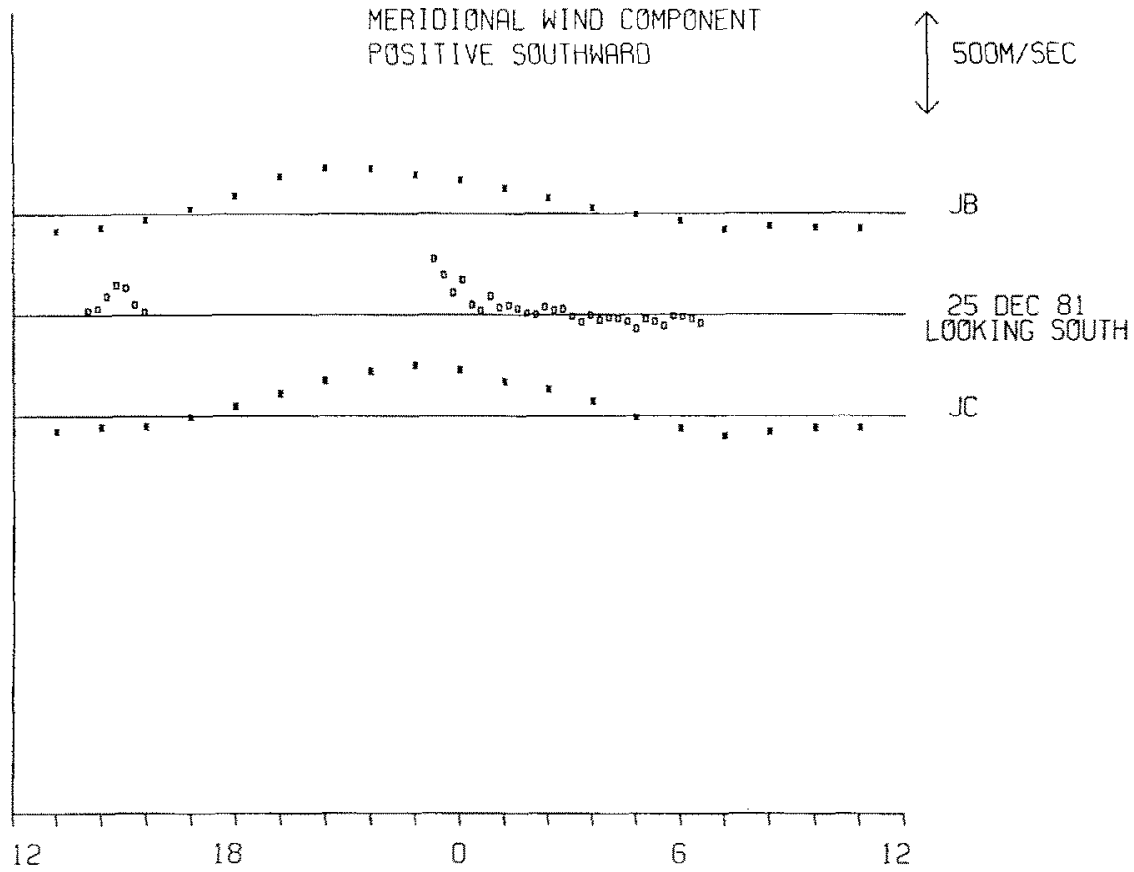

(B)

UNIVERSAL TIME

Fig. 28. SAME As Fig. 13, meridional winUS HKOM the KirUna GBFPI FOK 25/26 DEC 1981. 


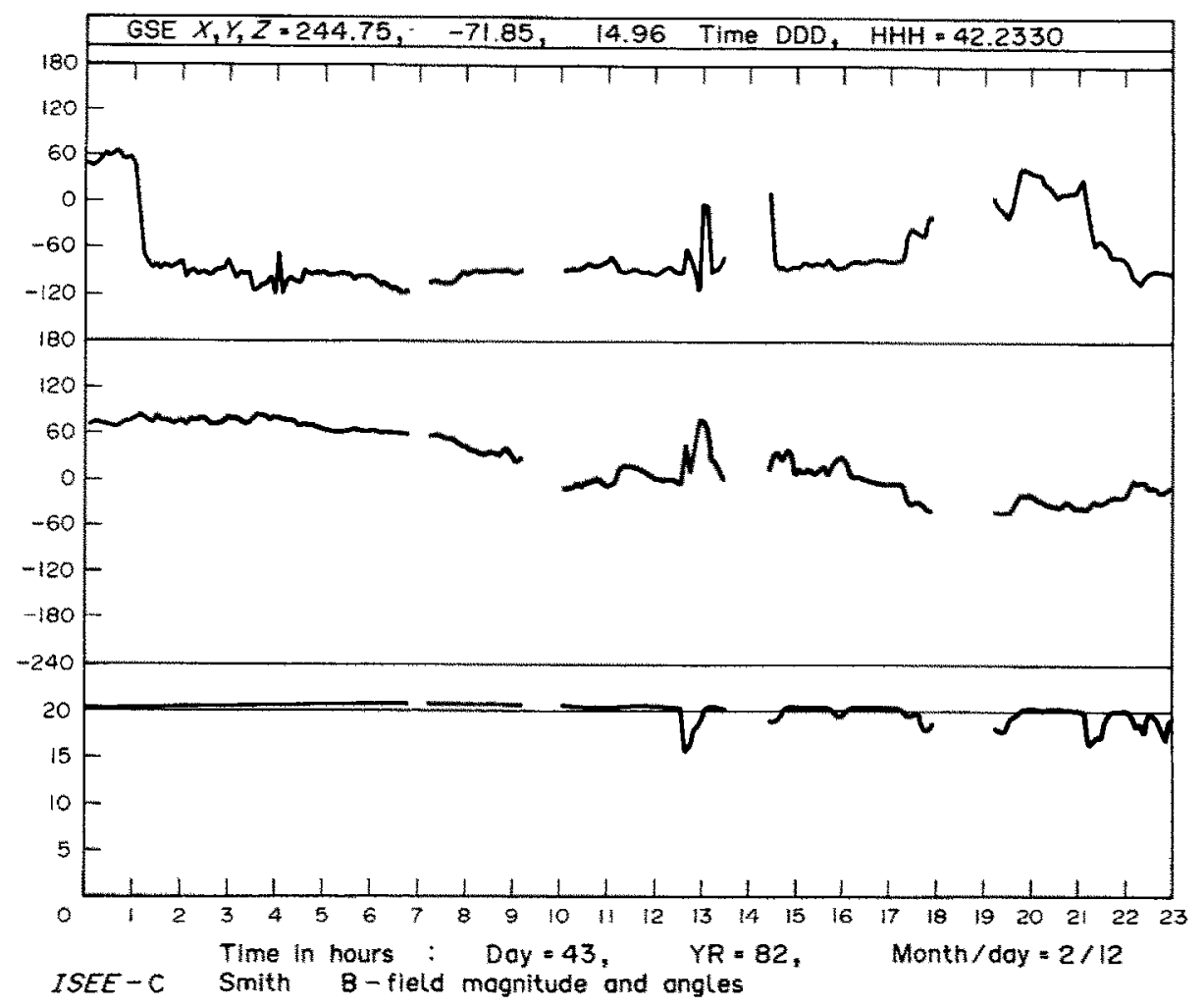

Fig. 29. Same as Fig. 10, IMF data from ISEE-3 for 12/13 Feb 1982 (Period 4).

associated with strong anti-sunward ion convection in the same region, a feature of the polar convection field when the $Y$ component of the IMF is positive. At such times, there are weak sunward wind velocities in the dawn auroral oval, associated with the constricted region of weak sunward ion convection in the dawn auroral oval at such times. When the IMF $B Y$ component is negative, the strongest anti-sunward ion convection within the polar cap is found on the dusk side of the polar cap. The thermospheric winds in the polar cap respond in a similar fashion. During this situation there is enhanced sunward ion flow within the dawn auroral oval, and this enhances sunward thermospheric wind flow velocities in this region. Periods of very strong eastward zonal winds in the post midnight auroral oval appear to occur uniquely in response to this situation. At Kiruna, the transition of westward zonal winds into equatorward and eastward winds one or more hours before magnetic midnight is another pronounced feature of a period when the " $Y$ " component of the IMF is negative. The transition to eastward winds occurs about $2 \mathrm{~h}$ earlier on average when $B Y$ is negative, than when $B Y$ is positive.
Examining the data from the Kiruna GBFPI on a night by night basis, the variance in the time when the thermospheric wind changes from westward, to southward and eastward is sometimes confused by the strong influence of short-period and violent perturbations associated with westward-travelling surges, which are themselves associated with strong substorms in the magnetic midnight sector of the auroral oval.

Given the limited temporal resolution of the successive $D E-2$ orbits, it appears that the polar ion convection pattern responds nearly immediately to a switch of the IMF BY component at the magnetopause. The polar thermospheric wind pattern, as observed by $D E-2$ and by the ground-based FPI's, responds to this change of ion convection within a further period of about two hours. This delay is consistent with the response we have observed in comparable theoretical simulations, and the subject will be discussed in detail in future studies.

Our present understanding of the complete thermospheric effects of the sense change of the " $Y$ " component of the IMF is clouded due to the lack of an empirical model describing the variance of magneto- 


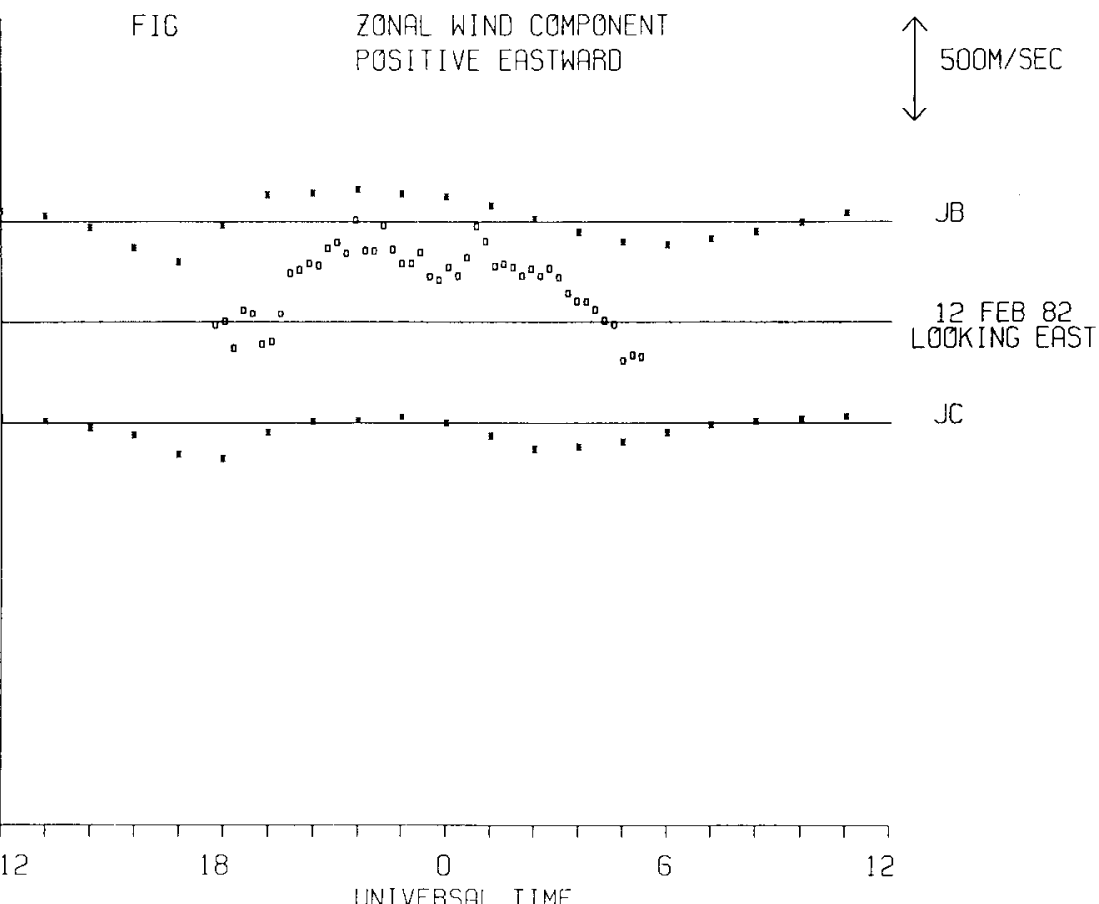

(A)

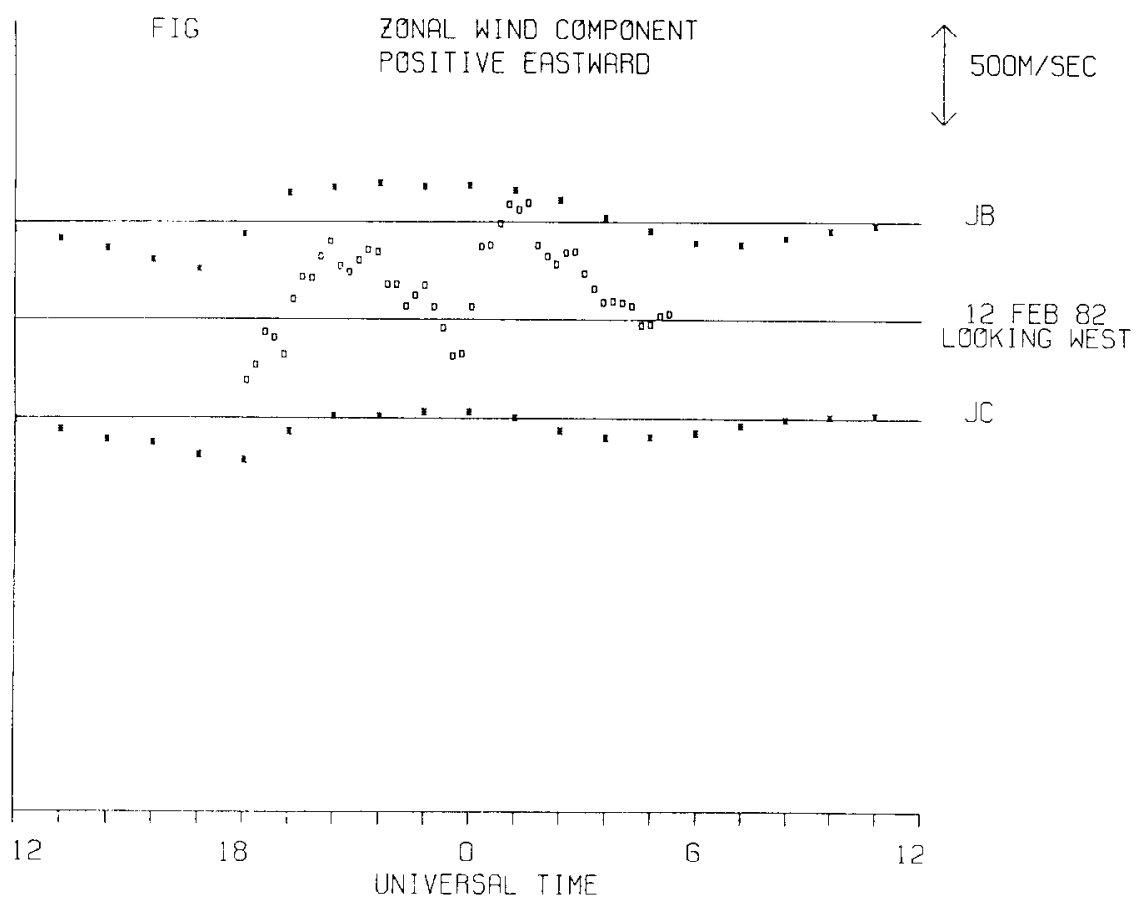

Fig. 30. Same as Fig. 12, zonal Winds from the GBFPI at KirUna fOR 12/13 Feb 1982. 


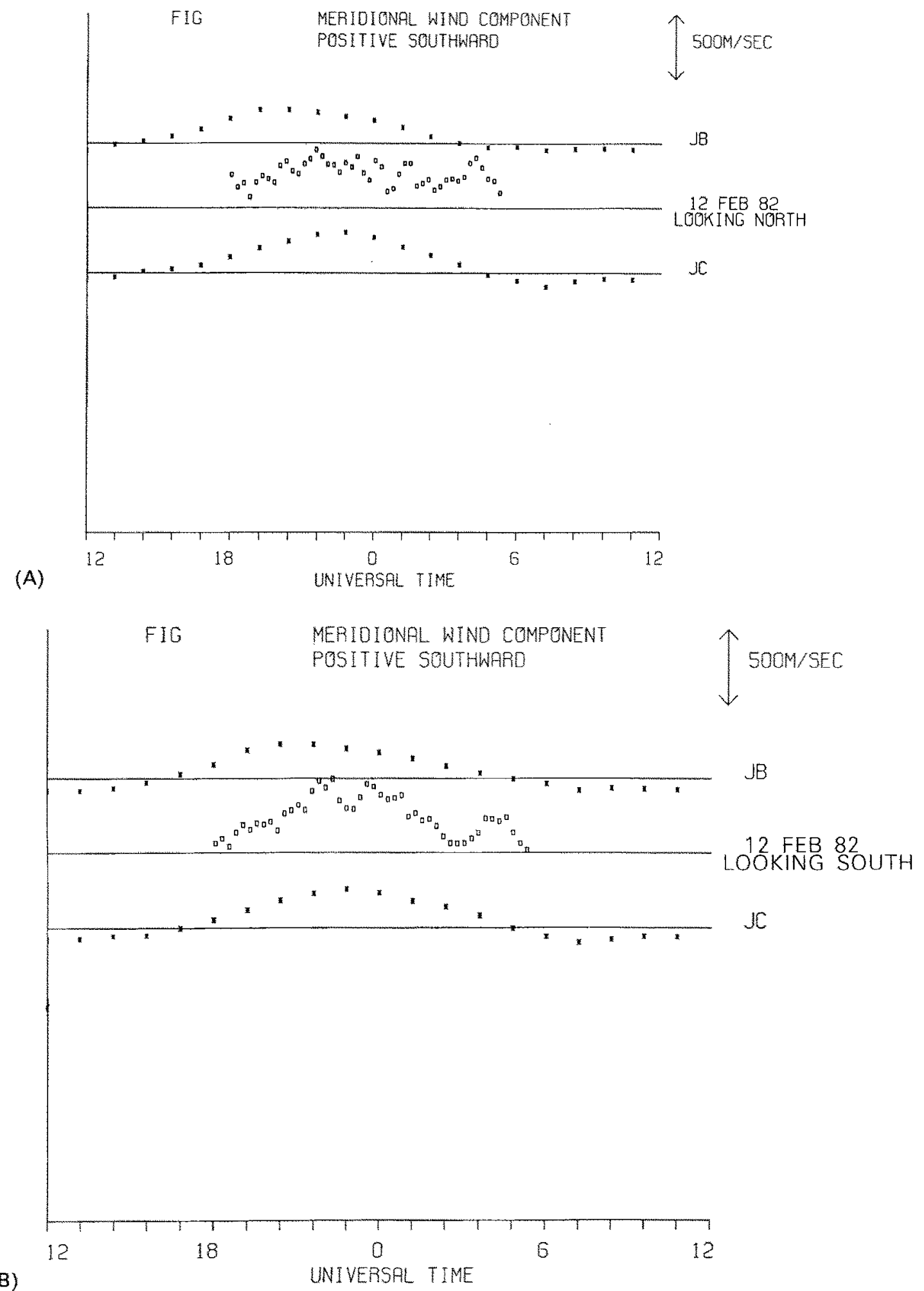

Frg. 31. SAME AS Fig. 13, MRRidional winds From the GBFPI at Kiruna for 12/13 Feb 1982. 
spheric particle precipitation with the sense of the IMF $B Y$, and covering the entire range of particle energies of importance for thermospheric energy and momentum studies. The data bases becoming available from DMSP, NOAA and the Dynamics Explorer satellites arc, in principle, capable of providing the required precipitation data as an important input to future thermospheric models.

The next major stage towards improving a quantitative understanding of the relative importance of external (solar wind/magnetosphere) and internal (thermosphere/ionosphere) processes will depend not only on improved empirical models of magnetospheric particle energy input, but also on the perfecting of interactive models of the polar ionosphere and thermosphere. The ionosphere, which provides the medium by which ion drag and friction and Joule heating effects modify thermospheric structure and dynamics, is extensively modified by magnetospheric convection and particle precipitation. Major feedback processes into the ionosphere occur as a result of the strong thermospheric winds and large changes in thermospheric composition, which are generated during major geomagnetic disturbances. These strong feedback processes make simple linear or onedimensional modelling of the ionospheric structure response to convection and precipitation of somewhat limited value.

Acknowledgements - It is a pleasure to acknowledge the many discussions with Dr. D. Winningham and Dr. D. Evans relating to the structure of energetic particle precipitation over the geomagnetic polar regions. The work at UCL was supported by grants from the U.K. Science and Engineering Research Council, and the grant of time on the CRAY 1-S of the University of London Computer Centre. The ground based Fabry - Perot interferometer at Kiruna was operated with the generous support of Kiruna Geophysical Institute, and the assistance of Ake Steen in particular with the observations is gratefully acknowledged. We appreciate the provision of data on the IMF from ISEE-3 by Dr. Tsurtani (Dr. E. J. Smith, Principal Investigator). N.C.M. Was supported for much of this work at Goddard Space Flight Center.

\section{REFERENCES}

Chiu, Y. T. (1975) An improved phenomenological model of ionospheric density. J. atmos. terr. Phys. 37, 1563.

DeVries, L. L. (1972) Structure and motion of the thermosphere shown by density data from the low-G accelerometer calibration system (LOGACS). Space Res. XII, 867 .

Fuller-Rowell, T. J. and Rees, D. (1980) A three-dimensional time-dependent, global model of the thermosphere. $J$. Atmos. Sci. 37, 2545 .

Fuller-Rowell, T.J. and Rees, D. (1981) A three-dimensional, time-dependent simulation of the global dynamical response of the thermosphere to a geomagnetic substorm. $J$. atmos. ter. Phys. 43, 701 .

Fuller-Rowell, T. J. and Rees, D. (1983) Derivation of a conservation equation for mean molecular weight for a twoconstituent gas within a three-dimensional, time-dependent model of the thermosphere. Planet. Space Sci. 31, 1209.

Fuller Rowell, T. I. and Rees, D. (1984) Interpretation of an anticipated long-lived E-region vortex, following simulation of an isolated substorm. Planet. Space Sci. 32, 69.

Fuller-Rowell, T. J., Rees, D., Quegan, S., Bailey, G. J. and Moffett, R. J. (1984) The effect of realistic conductivities on the high-latitude neutral thermospheric circulation. Planet. Space Sci. 32, 469.

Hays, P. B. Killeen, T. L. and Kennedy, B. C. (1981) The Fabry-Perot interferometer on Dynamics Explorer. Dynamies Explorer-Space Sci. Instrum. $5,395$.

Hays, P. B. Meriwether, J. W. and Roble, R. G. (1979) Nightime thermospheric winds at high latitudes. $J$. geophys. Res. 84, 1905.

Hays, P. B., Killeen, T, L, Spencer, N. W., Wharton, L. E. Roble, R. G., Emery, B. A., Fuller-Rowell, T. J., Rees, D. Frank, L. A. and Craven, J. D. (1984) Observations of the dynamics of the polar thermosphere. J. geophys, Res. 89, 5597.

Heelis, R. A., Lowell, J. K and Spiro, R. W. (1982) A model of the high latitude ionospheric convection pattern. $J$. geophys. Res. 87, 6339 .

Heppner, J.P. (1977) Empirical models of high latitude electric fields. I. geophys, Res. 82,1115.

Heppner, J. P. and Miller, M. L. (1982) Thermospheric wints at high latitudes from chemical release observations. $J$. geophys. Res. 87, 1633.

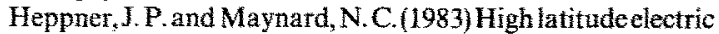
field models. Paper presented at the Chapman Conference on Magnetospheric Currents, AGU, Irvington, Va., April $5-8,1983$.

Iernandez, G. and Roble, R. G. (1978) Relationship between midlatitude thermospheric winds and the time rate of change of D(st), Geophys. Res. Lett. 5, 835.

Hoffman, R. A. and Schmerling, E. R. (1982) Dynamics Explorer Program : An overview. D ynamics Explorer-Space Sci. Instrum. 5, 345.

Kelley, M. C., Jorgensen, T. S. and Mikkelsen, I. S. (1977) Thermospheric wind measurements in the polar region. $J$. atmos. terr. Phys. 39, 211.

Killeen, T. L, Hays, P. B., Kennedy, B. C. and Rees, D. (1982) Stable and rugued etalon for the Dynowics Explorer interferometers-2. Performance. Appl. Opt, 21, 3903.

King-Hele, D. G. and Walker, D. M. C. (1983) Upperatmosphere zonal winds from satellite orbit analysis. Planet. Space Sci. 31, 509 .

Meriwether, J. W, Heppner, J. P., Stolarik, J. D. and Wescott, E. M. (1973) Neutral winds above $200 \mathrm{~km}$ at high latitudes. J. geophys. Res. 78,6643.

Mikkelsen, I. S., Jorgensen, T. S., Kelley, M. C., Larsen, M. F., Pereira, E. and Vickery, J. (1981) Neutral winds and electric fields in the dusk auroral oval-1. Measurements, $J$. geophys. Res. 86, 1513.

Nagy, A. F., Cicerone, R. J, Hays, P. B, McWatters, K. D., Meriwether, J. W., Relon, A. E and Rino, C. L (1974) Simultaneous measurement of ion and neutral motions by radar and optical techniques. Radio $S c i_{.} 9,315$.

Pereira, E., Kelley, M. C., Rees, D., Mikkelsen, I, S., Jorgensen, T.S. and Fuller-Rowell, T.J.(1980) Observations of neutral wind profles between 115 and $175 \mathrm{~km}$ altitude in the dayside auroral oval. $J_{\star}$ geophys. Res. 85, 2935. 
Quegan, S., Bailey, G. J., Moffett, R. J., Heelis, R. A., FullerRowell, T. J., Rees, D. and Spiro, R. W. (1982) A theoretical study of the distribution of ionization in the high latitude ionosphere and the plasmasphere: first results on the midlatitude trough and the light-ion trough. J.atmos. terr. Phys. 44, 619.

Rees, D. (1971) Ionospheric winds in the auroral zone. J. Brit. Interplan. Soc. 24, 233.

Rees, D. (1973) Neutral wind structure in the thermosphere during quiet and disturbed geomagnetic periods, in Physics and Chemistry of Upper Atmospheres (Edited by McCormac, B. M.), pp. 11-23. Reidel, Dordrecht.

Rees, D., Fuller-Rowell, T. J. and Smith, R. W. (1980) Measurements of high latitude thermospheric winds by rocket and ground-based techniques and their interpretation using a three-dimensional, time-dependent dynamical model. Planet. Space Sci. 28, 919.

Rees, D., Rounce, P. A., Charleton, P., Fuller-Rowell, T. J., McWhirter, 1. and Smith, K. (1981) Mesospheric and thermospheric winds during the energy budget campaign : ground-based Fabry-Perot observations supported by dynamical simulations with a three-dimensional, timedependent thermospheric model. Extended abstract, in BMFT-FB-W 81-052: Sounding Rocket Program Aeronomy Project: Energy Budget Campaign 1980 Experiment Summary(Edited by Offerman, D. and Thrane, E. V.), pp. 161-169.

Rees, D., Rounce, P. A. Charleton, P., Fuller-Rowell, T. J., McWhirter, L and Smith, K. (1982) Thermospheric winds during the Energy Budget Campaign: ground-based Fabry-Perot observations supported by dynamical simulations with a three-dimensional, time-dependent thermospheric model. J. Geophys. 50, 202.

Rees, D., Philbrick, C. R., Carlson, M., Charleton, P. and Fuller-Rowell, T. J. (1983b) In situ and remote sensing of thermospheric winds during the Energy Budget Campaign. Adv. Space Res. 2, No. 10, pp. 129-132.

Rees, D., Fuller-Rowell, T. J., Gordon, R., Killeen, T. L., Hays, P. B., Wharton, L. and Spencer, N. W.(1983a) A comparison of wind observations of the upper thermosphere from the Dynamics Explorer satellite with the predictions of a global time-dependent model. Planet. Space Sci. 31, 1299.
Rees, D, Charleton, P., Lloyd, N., Steen, A. and Witt, G. (1983c) Interferometric and Doppler imaging Studies of the Auroral Thermosphere from Kiruna Geophysical Institute. Proc. VIth ESA Symposium on Rocket and Balloon Programmes (ESA SP-183), 53-57.

Rees, D., Fuller-Rowell, T. J., Smith, M. F., Gordon, R., Killeen, T. L., Hays, P. B., Spencer, N. W., Wharton, L. and Maynard, N. C. (1985a) The westward thermospheric jetstream of the evening auroral oval. Planet.Space Sci.33, 425.

Rees, D., Gordon, R., Fuller-Rowell, T. I., Smith, M. F., Carignan, G. R., Killeen, T. L., Hays, P. B. and Spencer, N. W. (1985b) The composition, structure, temperature and dynamics of the upper thermosphere in the polar regions during October to December 1981. Planet. Space Sci. 33, 617.

Roble, R.G. and Rees, M.H. (1977) Time-dependent studies of the aurora : effects of particle precipitation on the dynamic morphology of ionospheric and atmospheric properties. Planet. Space Sci. 25, 991.

Rohle, R. G., Dickinson, R. E., Ridley, E. C., Fmery, B. A., Hays, P. B., Killeen, T. L. and Spencer, N. W.(1983) The high latitude circulation and temperature structure of the thermosphere near solstice. Planet. Space Sci. 31, 1479.

Smith, M. F. (1984) A study of the momentum and energy sources in the thermosphere using a global model. Ph.D. Thesis, University College London.

Smith, M. F., Evans, D. and Rees, D. (1985) In preparation.

Smith, R. W. and Sweeney, P. J. (1980) Winds in the thermosphere of the Northern Polar Cap. Nature Lond. 284, 437.

Spencer, N. W., Wharton, L. E., Niemann, H. B., Hedin, A. E, Carignan, G. R. and Maurer, J. C. (1981) The Dynamics Explorer wind and temperature spectrometer. Dynamics Explorer-Space Sci. Instrum. 5, 417.

Spiro, R. W., Heelis, R. A. and Hanson, W. B. (1978) lon convection and the formation of mid-latitude $F$-region ionization trough. J. geophys. Res. 83, 4255.

Spiro, R. W., Reiff, P. F. and Maher, L. J. (1982) Precipitating electron energy flux and auroral zone conductances-an empirical model. J. geophys. Res. 87, 8215 .

Volland, H. (1978) A model of the magnetospheric electric convection field. J. geophys. Res. 83, 2695. 